$10-7-2016$

\title{
Federal Home Loan Bank Advances and Bank and Thrift Holding Company Risk: Evidence From the Stock Market
}

Scott Deacle

Ursinus College, sdeacle@ursinus.edu

Elyas Elyasiani

Temple University

Follow this and additional works at: https://digitalcommons.ursinus.edu/bus_econ_fac

Part of the Economic Theory Commons, Finance and Financial Management Commons, Portfolio and Security Analysis Commons, and the Real Estate Commons

Click here to let us know how access to this document benefits you.

\section{Recommended Citation}

Deacle, Scott and Elyasiani, Elyas, "Federal Home Loan Bank Advances and Bank and Thrift Holding Company Risk: Evidence From the Stock Market" (2016). Business and Economics Faculty Publications. 33.

https://digitalcommons.ursinus.edu/bus_econ_fac/33 


\title{
Federal Home Loan Bank Advances and Bank and Thrift Holding Company Risk: Evidence from the Stock Market
}

\begin{abstract}
Scott Deacle* and Elyas Elyasiani**
Using bivariate GARCH models of stock portfolio returns and risk, we find that bank and thrift holding companies that relied the most on Federal Home Loan Bank (FHLB) advances exhibited less total risk and market risk than those that relied on them the least between 2001 and 2012. When we control for differences in holding company size, stock trading volume, residential mortgage lending, and holding company type (bank vs. thrift), the most FHLB-reliant holding companies sustain the aforesaid risk advantages except during the crisis of 2007-2009, when they exhibit greater idiosyncratic risk. The latter finding suggests that investors perceived the high reliance of the borrowing institutions on advances as a sign of distress. Portfolios that consist of only bank holding companies show qualitatively similar results.
\end{abstract}

\section{Introduction}

Federal Home Loan Banks (FHLBs) serve as a significant source of funding and liquidity for U.S. banks and thrifts. At the end of the second quarter of 2015, aggregate loans made by the FHLBs, called "advances," stood at $\$ 592$ billion (Federal Housing Finance Agency 2015). In addition, the FHLBs help their members maintain liquidity during credit crunches. For example, after the major credit rating agencies downgraded subprime mortgage-backed securities in the second half of 2007, the total value of FHLB advances outstanding grew by $36.7 \%$, from $\$ 640$ billion in July 2007 to $\$ 875$ billion in December 2007. This growth occurred before the Federal Reserve opened its Special Liquidity Facilities and before the Treasury Department intervened through the Troubled Asset Relief Program. The level of advances outstanding surpassed the $\$ 1$ trillion mark in November 2008 (Ashcraft, Bech and Frame 2010). FHLBs raise money for their members with several forms of

\footnotetext{
*Ursinus College, or sdeacle@ursinus.edu.

**Fox School of Business and Management, Temple University, or Elyas@temple.edu.
} 
government backing, creating moral hazard that could lead to risky lending, if not properly supervised. The magnitude of the FHLBs' operations and the moral hazard created by these arrangements motivate the current study. We examine the stock returns of bank and thrift holding companies (BHCs and THCs) that control FHLB members to determine the association between FHLB advance-taking and holding company (HC) risk. Total risk (the volatility of stock returns) and systematic risk (market beta) are both considered.

The FHLB system originated in the Great Depression, when Congress and President Hoover created it to ensure liquidity in the mortgage market and to facilitate home ownership (Hoffman 2001). The system initially included 12 FHLBs, each serving a different region, which were chartered by the federal government but almost entirely owned and governed by member financial institutions. ${ }^{1}$ Initially, membership was available only to thrifts, which were the biggest residential mortgage lenders, but Congress enacted changes in the 1980s and 1990s that effectively opened membership to nearly all U.S. depository institutions (DIs). The strength of the connection between FHLB funding and mortgage lending has since declined, as Frame, Hancock and Passmore (2012) show, while the system has dramatically increased its membership and financing activity. According to the Federal Housing Finance Agency (FHFA), system membership rose from about 3,200 institutions in 1989 to about 7,600 in 2012 and stood at 7,203 in the first quarter of 2016. ${ }^{2}$ Through a central Office of Finance, FHLBs issue debt on the global capital markets. They then distribute this money to their members in the form of advances or, in some cases, make their own investments. Federal legislation grants FHLBs several advantages that reduce the default risk and increase the liquidity of their debt. These include a line of credit for FHLBs at the Treasury, eligibility of FHLB debt for open-market purchase by the Federal Reserve, and a "super-lien" that gives FHLBs priority over other creditors in the event of a member's failure.

Some researchers have suggested that the organization and federal backing of the FHLB system elevate credit risk, whereas others have challenged this view, arguing that there are mechanisms in place to manage this risk and to even reduce market risk and liquidity risk. Elevated credit risk may emerge as a consequence of the government backing, because FHLB managers do not experience the discipline of increased default risk premiums on their

\footnotetext{
${ }^{1}$ The Des Moines and Seattle FHLBs merged in 2015, reducing the number to 11.

${ }^{2}$ Data taken from reports posted on http://www.fhfa.gov/DataTools/Downloads/Pages/ Federal-Home-Loan-Bank-Member-Data.aspx. Downloaded August 3, 2016.
} 
borrowings (Flannery and Frame 2006). Similarly, FHLB member DIs are not subject to market discipline on advances, as interest rates on advances do not vary with borrowing members' risk (Stojanovic, Vaughan and Yeager 2008). The FHLBs' super-lien also creates an additional burden on the Federal Deposit Insurance Corporation's (FDIC's) deposit insurance fund because it requires FHLBs to be made whole before depositors when FDIC-insured institutions fail or enter receivership (Bennett, Vaughan and Yeager 2005). However, as Scott and Hein (2009 and 2011) write, FHLBs mitigate their credit risk by requiring collateral on advances and have the ability to limit advances to members that are too risky. Moreover, FHLBs are subject to safety and soundness supervision, currently by the FHFA. FHLB emergency funding, especially at critical junctures such as liquidity crunches, may also help stabilize FHLB members. At the same time, emergency funding may allow troubled DIs to continue operating in risky ways for too long or to delay resolutions.

Empirical evidence on the relationship between firm risk and FHLB membership and advance-taking is mixed. Ashcraft, Bech and Frame (2010) report that, of the $\$ 235$ billion increase in advances in the second half of 2007, $\$ 42.4$ billion went to Washington Mutual Bank, which went into FDIC receivership in September 2008, and \$18.9 billion went to Countrywide Federal Savings Bank, which was purchased by Bank of America in early 2008 after several months of distress. In these cases, advances appear to have gone to institutions that the FHLBs should have known were highly risky. Using data for 1992-2003, Bennett, Vaughan and Yeager (2005) find that the ratio of banks' FHLB advances to total assets is positively correlated with the likelihood of an FDIC supervisory rating downgrade, reflecting increased risk. Contrary to this, using matched-pair analysis of data from 1992 to 2004, Scott and Hein (2009) find that banks that joined FHLBs do not subsequently exhibit significant increases in leverage, total assets growth or loan loss provisions. Using regression analysis of data from 1992 to 2005, Stojanovic, Vaughan and Yeager (2008) report that after banks become FHLB members, they exhibit economically significant increases in liquidity risk and leverage risk. On the other hand, however, they find an economically insignificant relationship between banks' reliance on advances and credit risk, identical probability of failure for FHLB members and nonmembers and a negative relationship between reliance on advances and interest rate risk.

In contrast to previous research that focuses on supervisory ratings and risk measures taken from financial statements, we focus on the stock market's assessment of the riskiness of HCs that control FHLB member institutions. We use a bivariate generalized autoregressive conditionally heteroskedastic 
(BV-GARCH) model of BHC and THC stock returns to estimate their risk measures such as conditional variance of returns and market beta. We form portfolios of HC stocks according to the degree to which the DIs included in each portfolio rely on FHLB advances for funding. One of the two baseline portfolios that we focus on comprises HCs that rely the most on FHLB funding. The other comprises HCs that rely on it the least. Using data from 2001 through 2012, we find that total risk (conditional variance of returns) and market risk (market beta) are lower for the former portfolio in each of the three periods into which we divide the sample: prefinancial crisis, crisis and post-crisis. These results, however, may have been influenced by the relatively small size of the HCs that relied on FHLB advances the most, the low trading volume of many of their stocks, difference in HC type (THC or $\mathrm{BHC}$ ) and the extent of their focus on mortgage lending. After accounting for these factors, most of our results remain qualitatively intact. Specifically, the results on market risk remain valid for all three sub-periods and the results on total risk continue to hold in the pre- and post-crisis periods. The notable exception is that during the crisis period the total risk of the HCs that are most reliant on advances exceeds that of their counterparts that are least-reliant on advances. This finding, combined with the result on the market risk of these HCs during the crisis, implies a relative increase in this group's idiosyncratic risk in this period. This finding is remarkable, because although one mission of the FHLBs is to curtail the liquidity risk of their members during crises, the greater idiosyncratic risk among the heaviest users of FHLB advances, after controlling for differences in mortgage lending, suggests that these lenders were perceived to be especially distressed. We find little evidence to suggest that the long-term nature of advances, which could help banks and thrifts to mitigate risk, drive any of our findings, nor do we find that FHLB funding gives banks an advantage or disadvantage in the management of interest rate risk. In the next section, we describe the hypotheses and the econometric model used to test them. The following sections describe the data sources, portfolio formation, empirical results and conclusions.

\section{Hypotheses}

Previous studies, discussed above, indicate that opposing forces drive the relationships between FHLB-member DIs' risk and their FHLB advancetaking so that the net effect is an empirical question. If FHLBs' policies toward advances discourage risky lending by DIs enough to more than offset the moral hazard that they possibly engender, we would expect to see the parent HCs exhibit less risk as their reliance on FHLB advances increases. We examine this relationship by estimating bivariate GARCH models, which 
permit us to test the association between HC risk and reliance on FHLB advances as described by hypothesis $\mathrm{H}_{1}$ :

$\mathrm{H}_{1}$ : Greater bank (thrift) reliance on FHLB advances is associated with lower total risk (the conditional variance of stock returns of the parent HCs).

Moreover, if FHLBs are cautious in their lending to members, they will avoid making large amounts of advances to members that are strongly exposed to market-wide risk factors, at least when the latter are not in distress. In this scenario, greater reliance on advances should be associated with less sensitivity to general market fluctuations and, hence, a lower level of systematic risk (market beta). This effect can be strengthened if long-term FHLB advances cushion members against liquidity and long-term funding problems. Likewise, if DI members of the FLHBs do not already hedge interest rate risk through the market place (using interest rate derivatives, for example), long maturity advances and interest rate swaps offered by the FHLBs could lower these DIs' interest rate risk. In this scenario, it is likely that HCs funding a greater proportion of their lending with advances will be exposed to a lower interest rate risk. Stock market data make it possible to estimate the portfolios' market risk and interest rate risk using two-factor models of portfolio stock returns, with the two factors being the returns on a market portfolio and a measure of the interest rate environment. This framework also allows us to test the association between market and interest rate risk on the one hand and reliance on FHLB advances on the other, as described by $\mathrm{H}_{2}$ and $\mathrm{H}_{3}$, respectively:

$\mathrm{H}_{2}$ : Greater bank (thrift) reliance on FHLB advances is associated with lower market risk (market beta) of parent HCs.

$\mathrm{H}_{3}$ : Greater bank (thrift) reliance on FHLB advances is associated with lower interest rate risk (interest rate beta) of parent HCs.

During the third quarter of 2007 , losses on subprime mortgage-backed securities initiated a panic in the market for repurchase agreements (repos). At that time, DIs saw interest rates on a variety of their funds rise (Gorton, 2010). As Figure 1 shows, the HCs in our sample dramatically increased their reliance on advances in the third quarter of 2007, and the usage of advances remained elevated until the second quarter of 2009. If FHLB advances are perceived as risk-reducing by market participants and few advances went to high-risk members, the negative relationship between risk and reliance on advances $\left(\mathrm{H}_{1}\right)$ is likely to strengthen during the crisis, when FHLB support is more 
Figure 1 aggregate FHLB advances for HCs in the sample: 2001-2012.

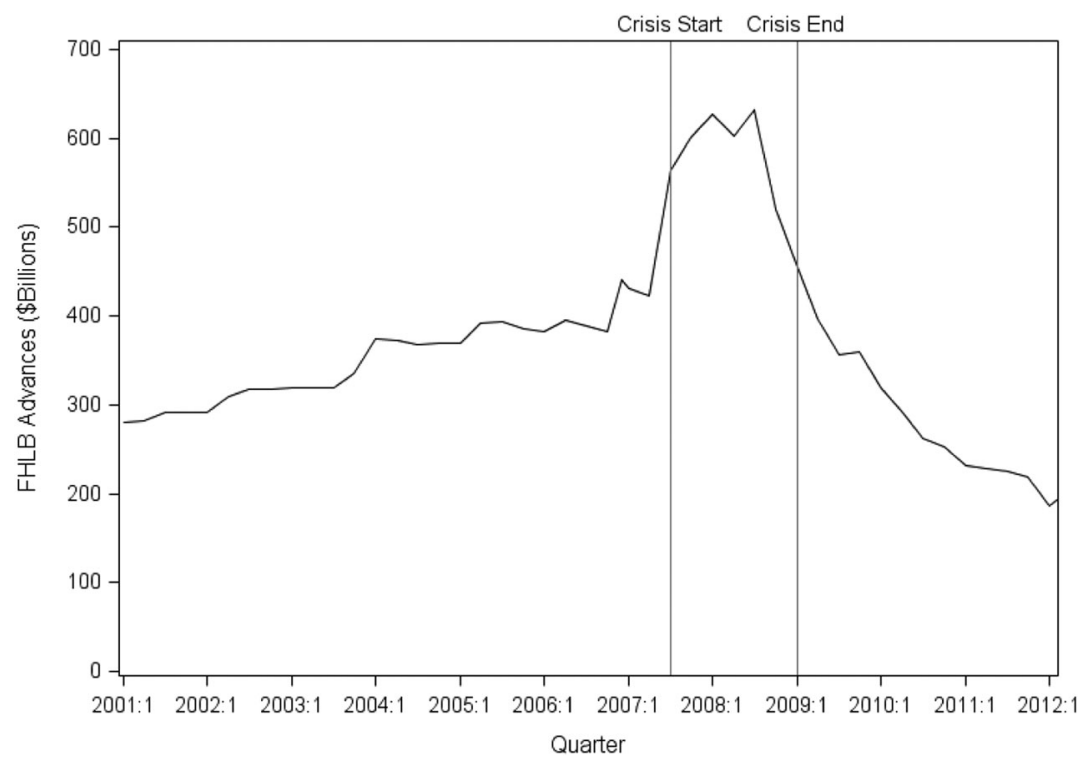

critical to members. It also follows that, if the riskiness of FHLB member DIs rises during the crisis, those receiving greater FHLB advances should witness smaller increases in risk, unless they are perceived as being in a state of distress by market participants. This point leads to hypothesis $\mathrm{H}_{4}$.

$\mathrm{H}_{4}$ : Greater bank (thrift) reliance on FHLB advances is associated with smaller increases in total risk (conditional variance of returns), market risk (market beta), and interest rate risk (interest rate beta) of parent HCs during the sub-prime mortgage crisis of 2007:Q3-2009:Q1.

\section{A Bivariate GARCH Model of HC Stock Returns}

GARCH models have frequently been used to study the behavior of asset returns (see, e.g., Bollerslev 1990, Engle 2001, Bauwens, Laurent and Rombouts 2006). The GARCH $(1,1)$ framework, used in this study, models the conditional variance of an asset's return as a function of the one-period lagged values of the squared residual from a linear conditional mean model (the $\mathrm{ARCH}$ term) and the one-period lagged values of the conditional variance estimate (the GARCH term). The conditional variance (volatility) of HCs' stock returns measures the HCs' total risk. The coefficients (betas) on the 
regresssors in the conditional mean equation measure the risk that investors assign to various risk factors. GARCH models offer advantages over simpler mean regression models because they allow the dynamics of conditional variance to be modeled. Moreover, these models do not need to make the restrictive assumption of normality of the asset returns as they are amenable to alternative distributional assumptions.

A number of GARCH studies investigate financial firms' stock return behavior and the interdependencies of those returns. An early example is Song (1994), which studies the market risk and interest rate risk of portfolios of DI stocks. Elyasiani, Mansur and Pagano (2007) use multivariate GARCH models to study inter-industry spillovers of risk on the stock returns of banks, securities firms and life insurance companies (LICs). Similarly, Carson, Elyasiani and Mansur (2008) examine the interdependencies in insurer stock returns within a system-GARCH model. Finally, Elyasiani, Mansur and Wetmore (2010) use multivariate GARCH models to study the equity returns and return volatilities of real estate investment trusts (REITs), BHCs, THCs and LICs.

We employ bivariate GARCH models to describe the conditional means and conditional variances for pairs of portfolio return series. The baseline portfolios are formed according to the degree to which HCs rely on FHLB advances, as measured by the ratio of advances to total liabilities (ATL). HCs relying the most on FHLB advances go into one portfolio, called HIGH_ATL, and HCs relying the least on them go into the other portfolio, $L O W \_A T L$. Conditional means of returns $\left(R_{i t}\right)$ for these portfolios, indexed by $i$ ( $i=1$ or 2 ), are initially modeled using a two-factor model that includes the market return $\left(\mathrm{RM}_{t}\right)$ and the lagged interest rates $\left(\mathrm{INT}_{t-1}\right)$ as the independent variables. The latter variable is lagged in order to avoid endogeneity bias, which may arise from contemporaneous correlation of shocks to financial markets, represented by the error term, and innovations in the interest rate. Market return and interest rate may be interpreted as risk factors. The coefficient on the market return measures, conditional on interest rates, the portfolio's sensitivity to macroeconomic fluctuations, which could have an effect on bank or thrift cash flows. The coefficient on the interest rate factor measures, conditional on market returns, the portfolio's sensitivity to changes in the interest rate environment, which could also be associated with changes in bank and thrift cash flows because of the duration mismatches between their assets and liabilities. As Bessler and Kurman (2014) write, over time different risk factors impact financial insitution stock returns as financial insitutions adopt different strategies for earning profits. Akella and Chen (1990), Song (1994), Browne, Carson and Hoyt (1999). Elyasiani, Mansur and Pagano (2007) and Bessler and Kurman (2014) find that various proxies for both market returns and changes in interest rates have significant effects on BHC stock returns, 
whereas other research has found a market effect but not an interest rate effect (Elyasiani and Mansur 2003). The BV-GARCH model used here, thus, includes the following five equations:

$$
\begin{aligned}
& R_{1 t}=\alpha_{1}+\beta_{11} \mathrm{RM}_{t}+\beta_{12} \mathrm{INT}_{t-1}+\varepsilon_{1, t}, \\
& h_{11, t}=v_{1}+\lambda_{1} \varepsilon_{1, t-1}^{2}+\delta_{1} h_{11, t-1}, \\
& R_{2 t}=\alpha_{2}+\beta_{21} \mathrm{RM}_{t}+\beta_{22} \mathrm{INT}_{t-1}+\varepsilon_{2, t}, \\
& h_{22, t}=v_{2}+\lambda_{2} \varepsilon_{2, t-1}^{2}+\delta_{2} h_{22, t-1}, \\
& h_{12, t}=\rho_{12} h_{11, t} h_{22, t}\left(-1<\rho_{12}<1\right), i=1,2, \\
& \varepsilon_{i, t} \mid \Omega_{t-1}^{\prime} \sim t(v) .
\end{aligned}
$$

In this model, conditional variances of the portfolios' returns, $h_{11, t}$ and $h_{22, t}$, are interpreted as the portfolios' total risk. Estimation of the model generates conditional variance estimates for each trading day in the sample. We perform $t$-tests of the significance of the differences in the mean conditional variance of these two portfolios to produce evidence regarding hypothesis $\mathrm{H}_{1}$ (greater reliance on advances is associated with lower total risk). Simultaneous estimation of the equations using the bivariate two-factor model enables us to use Wald tests of cross-equation equality of the two portfolios' market and interest rate betas $\left(\beta_{11}=\beta_{21}\right.$ and $\left.\beta_{12}=\beta_{22}\right)$. These tests provide evidence regarding hypotheses $\mathrm{H}_{2}$ and $\mathrm{H}_{3}$ (greater reliance on advances is associated with lower market risk and lower interest rate risk, respectively). The conditional variance-covariance relationship (Equation (5)) allows the conditional variances $\left(h_{11, t}\right.$ and $\left.h_{22, t}\right)$ to change over time but assumes the correlation $\left(\rho_{12}\right)$ between the two series remains unchanged over the estimation period. The value of $\rho_{12}$ is estimated along with the other parameters. The constant correlation specification of multivariate GARCH models ensures that the conditional variance-covariance matrix of returns is positive semi-definite and, hence, does not imply negative return variances (Bollerslev 1990). We assume the residuals follow the Student $t$-distribution, because the return distributions of some portfolios exhibit fat tails in some sub-periods for which we estimated the model, particularly those that come from the crisis period (2007:Q3-2009:Q1). For subsamples in which portfolio returns do not exhibit fat tails, the $t$-distribution still fits, because as the degrees of freedom increases, the $t$-distribution converges to the normal distribution. The models are estimated employing the method of maximum likelihood using the optimization algorithm of Berndt et al. (1974). Initial values are taken from estimates of the bivariate GARCH models using the simplex algorithm.

We estimate the model for three subsample periods reflecting changes in the stability of the financial system and the role of the FHLBs in shoring up that 
system. ${ }^{3}$ Figure 1 graphically illustrates the aggregate advances for the HCs during our sample period (2001-2012). The vertical lines delineate the three sub-periods. The first period, the pre-crisis period, starts at the beginning of the data set in January 2001, when FHLB advances data for banks were first made available in the Call Reports, and runs through the end of the second quarter of 2007. The second period, the crisis period, begins with the third quarter of 2007, when news of mounting losses on subprime mortgage-backed securities initiated a panic in the market for repurchase agreements (repos), for which such securities served as collateral (Gorton 2010), at the end of the first quarter of 2009. Ashcraft, Bech and Frame (2010) document an increase in FHLB funding during this period. The third period, the postcrisis period, begins with the start of the second quarter of 2009, when FHLB advances returned to their precrisis level, and ends at the end of 2012.

\section{Data}

Because we use market data on BHC and THC stocks, our sample is limited to banks and thrifts which are publicly traded. Market data present some advantages over the accounting and supervisory data used in previous research on the relationship between bank risk and FHLB advances (Bennett, Vaughan and Yeager, 2005; Stojanovic, Vaughan and Yeager, 2008). Specifically, accounting-based data are backwards looking, rather than forward looking, lack information about systemic or macroeconomic risk as determined by expectations of future market movements, and are subject to "window dressing" by managers who time the reporting of both good and bad news through discretions provided by accounting rules. Confidential supervisory ratings have the disadvantage of being unavailable to the public. Market data, however, incorporate investors' knowledge of economy-wide conditions, their expectations for future $\mathrm{HC}$ performance, and information that $\mathrm{HC}$ managers do not release in accounting statements, such as news that emerges after the statements are released. In addition, by using HC-level, rather than subsidiarylevel, data, we avoid over- or under-estimation of bank risk that occurs when HCs, often under pressure from regulators or regulations, shift assets among subsidiaries (Ashcraft 2008).

We assemble HC stocks into portfolios according to their dependence on FHLB advances. Studying portfolio returns offers several advantages over studying the individual $\mathrm{HC}$ returns. Portfolios combine data from dozens of HCs into a few assets that are relatively easy to compare. In addition,

\footnotetext{
${ }^{3}$ We would like to thank an anonymous referee for the suggestion to break up the sample into three subperiods.
} 
portfolios smooth out sudden fluctuations, or noise, in returns from shortterm shocks to individual HCs, while allowing examination of differences in behavior among baskets of different categories of HCs. To avoid domination of the results by large $\mathrm{HCs}$, we give equal weight to each stock in the portfolio, rather than weighting them by size.

Stock market data come from the Center for Research on Security Prices (CRSP) by way of Wharton Research Data Services (WRDS). Portfolio returns $(R)$ and the return on the market portfolio $(R M)$, measured by the return on the CRSP value-weighted market portfolio, include dividends. The interest rate variable (INT) is the yield on the one-year constant maturity Treasury, the data for which come from the Board of Governors of the Federal Reserve System. ${ }^{4}$ FHLB membership information is from the FHFA and is used to exclude HCs that do not control FHLB members and, therefore, cannot obtain FHLB advances, from the sample. ${ }^{5}$ Although HCs with no FHLB-member subsidiaries represent a potentially useful control group, there are only about 1,255 observation on such HCs over the 48 quarters in this time period, with fewer than 12 in many quarters. This is too few to form useful portfolios for comparison. For commercial banks, accounting data are drawn from Call Reports - from the Federal Reserve Bank of Chicago before 2010, and from the Federal Financial Institutions Examinations Council (FFIEC) thereafter. For parent BHCs, accounting data come from BHC (Y-9C) reports supplied by the Federal Reserve Bank of Chicago. For thrifts, data come from Thrift Financial Reports (TFRs) supplied by the Office of Thrift Supervision (OTS) for 2001-2009 and by the Federal Financial Institutions Examination Council (FFIEC) for the remainder of the period examined. ${ }^{6}$ Data on THCs, which did not file publicly-released regulatory reports until 2012, are based on financial statements required of publicly-traded firms, compiled in the Standard $\&$ Poor's Compustat database. BHC regulatory data were matched to stock market data using a listing of BHCs' Federal Reserve and CRSP identification numbers produced by the Federal Reserve Bank of New York. THC accounting data were matched to CRSP data using THC ticker symbols supplied by the OTS and the authors' own research. In any given time period, HCs are

\footnotetext{
${ }^{4}$ Obtained in October 2015 from http://www.federalreserve.gov/releases/h15/data.htm.

${ }^{5}$ FHLB membership from 2009:Q4 forward is available from the FHFA Web site http://www.fhfa.gov/DataTools/Downloads/Pages/Federal-Home-Loan-BankMember-Data.aspx. Data prior to that were obtained via correspondence with the FHFA.

${ }^{6}$ The Chicago Fed stopped posting Call Report data on its Web site at the end of 2010. It continues to post BHC report data on its Web site. The OTS supplied us with TFR data in the early stages of this study, before the data became more readily available through the FFIEC Web site.
} 
included in the sample if their stock market data and accounting data are both available.

\section{Empirical Analysis}

\section{Descriptive Statistics}

The sample runs from 2001 to 2012 and includes 24,465 quarterly observations of financial statement data on a total of 968 HCs. There are 48 quarters in the sample. Descriptive statistics for the HCs in the sample are presented in Table 1. In terms of asset size, the sample includes a broad range of BHCs and THCs, but mid-sized and large HCs are disproportionately represented because they are more likely to issue stock. HCs in the sample reported total assets between $\$ 65.2$ million and $\$ 2.4$ trillion, with a mean of $\$ 25.8$ billion. Aggregate advances held by all HCs in the sample ranged from $\$ 184$ billion to $\$ 618$ billion, depending on the quarter of the observation. Given that system-wide FHLB advances outstanding ranged from $\$ 418$ billion to $\$ 1.0$ trillion during this time, ${ }^{7}$ firms included in our sample were using 44-61.1\% of all the advances outstanding, depending on the date. As noted above, we measure HCs' reliance on advances by their advances to liabilities ratio (ATL). To obtain ATL, we aggregate the FHLB advances reported by each of the HC's DI subsidiaries and divide the sum by the HC's total liabilities. HCs in the sample have a mean ATL of $9.3 \%$, a median ATL of $6.9 \%$ and an ATL range of zero to $62.0 \%$. Only $10 \mathrm{HCs}$ in the sample report ATL greater than $50 \%$ in a quarter, and the 99th percentile of ATL is $38.4 \%$. We retain all observations because our analysis is performed on portfolios that mitigate the effects of outliers.

We form two portfolios, $H I G H \_A T L$ and $L O W \_A T L$, according to ATL values. HIGH_ATL contains HCs in the highest quartile of ATL among HCs that control an FHLB member in each quarter. $L O W \_A T L$ contains HCs in the lowest quartile in each quarter. We recalculate each HC's ATL each quarter and change the portfolio compositions accordingly. We include new HCs when they appear in both the CRSP data and the regulatory reports. When HCs fail or are targets in mergers or acquisitions, they are dropped from the sample when they leave either database. There is no significant difference between the $H I G H \_A T L$ and $L O W \_A T L$ portfolios in terms of the number of HCs that drop out, so we conclude survivorship issues do not bias our results. Tables 2 and 3 present annual statistics on selected characteristics of HCs in the panel as a whole as well as those in the HIGH_ATL and LOW_ATL

\footnotetext{
${ }^{7}$ These figures come from combined FHLB system financial reports posted by the FHLB Office of Finance on its Web site, http://www.fhlb-of.com.
} 
12 Deacle and Elyasiani

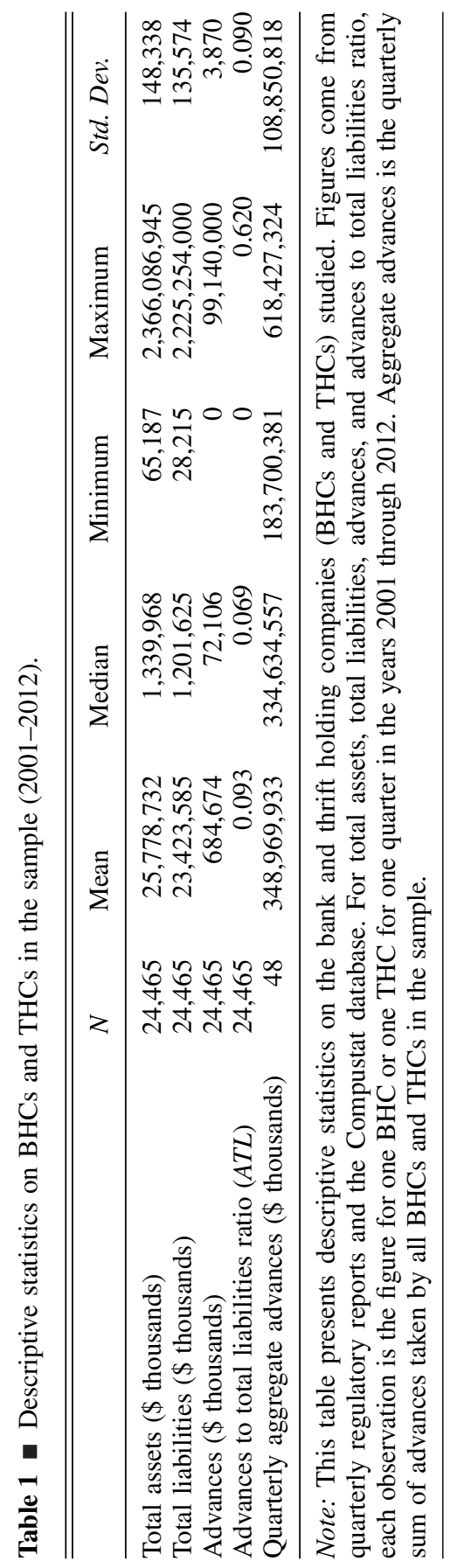




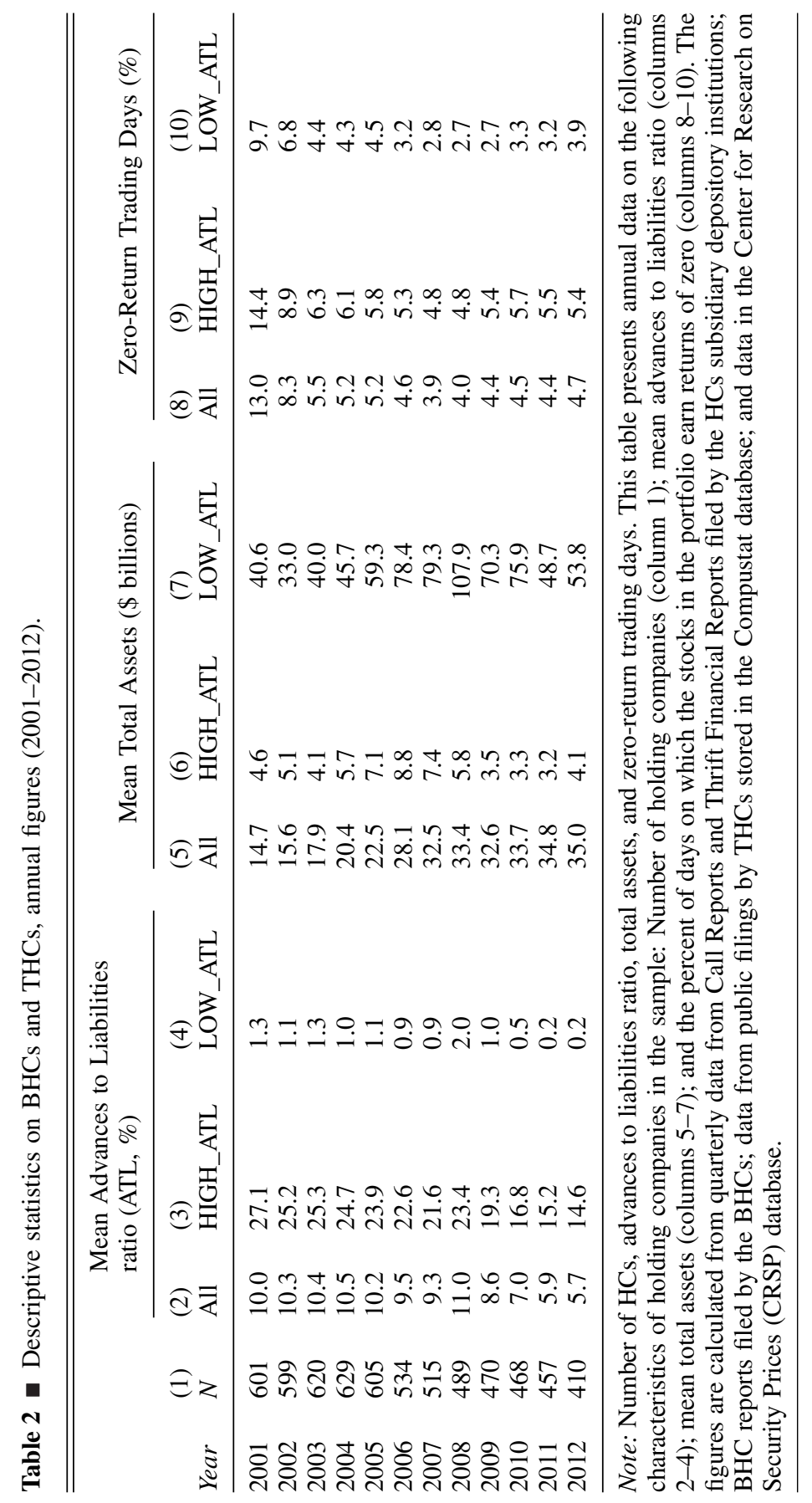


Table 3 - Descriptive statistics on BHCs and THCs, annual figures (2001-2012).

\begin{tabular}{|c|c|c|c|c|c|c|}
\hline \multirow[b]{3}{*}{ Year } & \multicolumn{3}{|c|}{ THC (\% of all HCs) } & \multicolumn{3}{|c|}{ Average Mortgage to Assets Ratio (\%) } \\
\hline & (1) & (2) & (3) & (4) & (5) & (6) \\
\hline & All & HIGH_ATL & LOW_ATL & All & HIGH_ATL & LOW_ATL \\
\hline 2001 & 24.7 & 63.3 & 21.4 & 41.9 & 46.4 & 35.5 \\
\hline 2002 & 25.2 & 57.0 & 21.4 & 42.0 & 44.7 & 36.2 \\
\hline 2003 & 25.5 & 53.6 & 24.0 & 41.7 & 42.5 & 35.9 \\
\hline 2004 & 24.7 & 53.7 & 19.4 & 43.4 & 43.8 & 38.0 \\
\hline 2005 & 24.3 & 54.2 & 18.0 & 45.6 & 45.5 & 40.1 \\
\hline 2006 & 26.4 & 58.0 & 20.6 & 46.2 & 47.0 & 37.7 \\
\hline 2007 & 27.1 & 52.4 & 25.8 & 47.4 & 50.2 & 37.8 \\
\hline 2008 & 27.5 & 51.6 & 26.6 & 47.9 & 50.0 & 39.0 \\
\hline 2009 & 26.4 & 50.7 & 24.7 & 46.4 & 48.5 & 39.2 \\
\hline 2010 & 23.6 & 46.2 & 19.5 & 45.5 & 48.9 & 40.1 \\
\hline 2011 & 24.8 & 43.6 & 22.2 & 43.4 & 47.3 & 37.5 \\
\hline 2012 & 18.8 & 41.5 & 10.1 & 44.7 & 47.4 & 41.1 \\
\hline
\end{tabular}

Note: THCs, mortgage to assets ratio. This table presents annual data on the following characteristics of holding companies in the sample: percentage of the HCs that are thrift holding companies (THCs) (columns 1-3), and mean ratio of 1-4 family residential mortgages to total assets (columns 4-6). The figures are calculated from quarterly data from Call Reports and Thrift Financial Reports filed by the HCs subsidiary depository institutions, BHC reports filed by the BHCs and data from public filings by THCs stored in the Compustat database.

portfolios, demonstrating how several properties of the sample change over time. The number of stocks in the panel fluctuates around a downward trend over time, ranging from a peak of 629 in 2004 to a low of 410 in 2012 (Table 2 , column 1). These figures are consistent with the trend of consolidation in the U.S. financial services industry.

We focus on differences in risk between the two baseline portfolios and how these differences changed after the onset of the crisis. Since the portfolios lose equal or nearly equal numbers of stocks over time, the increase in variance of returns that is attributable to reduced number of stocks should be roughly equal and, hence, should have little effect on our results. Industrywide reliance on FHLB advances, as measured by the average ATL ratio among the $\mathrm{HCs}$ in the entire sample, peaked at $11.0 \%$ in 2008 , when the FHLB system increased advances in response to the liquidity crunch (Table 2, column 2). FHLB-reliance declined in 2009 as the Federal Reserve and Treasury's emergency liquidity programs went into effect.

HCs that relied the most on advances were smaller than those that relied the least on advances. HCs in the lowest ATL quartile have total assets 
averaging between $\$ 33.0$ billion and $\$ 107.9$ billion, whereas the HCs in the highest ATL quartile have average total assets ranging from $\$ 3.2$ billion to $\$ 8.8$ billion (Table 2, columns 6 and 7). As we will discuss in more detail in the section on robustness checks, the size difference may affect market prices of these HCs' stocks due to size-related differences in the likelihood of government bailouts, risk-taking behavior, and zero-return observations. At this stage, we note that zero return trading days comprise between $5.4 \%$ and $14.4 \%$ of observations in a given year for stocks in the HIGH_ATL portfolio and between $3.9 \%$ and $9.7 \%$ for stocks in the $L O W \_A T L$ portfolio (Table 2, columns 9 and 10). The differences stem from differences in trading volume which may affect our estimates of risk measures.

Columns 1 to 3 of Table 3 show the percentages of HCs that are THCs. Depending on the year, between $10.1 \%$ and $26.6 \%$ of $\mathrm{HCs}$ in the lowest quartile and between $41.5 \%$ and $63.3 \%$ of the HCs in the highest quartile are THCs. Because THCs and BHCs operated under different supervisory structures for much of the period studied, we will test later whether our baseline results are robust when we control for this difference. We also note that after holding steady for most of the period examined, the proportion of THCs in the overall sample declines from $24.8 \%$ in 2011 to $18.8 \%$ in 2012 (Table 3, column 1). This decline follows the passage of the Dodd-Frank Act (The Wall Street Reform and Consumer Protection Act 2010), which closed the primary thrift and THC regulator, the OTS, in 2012 and placed thrifts and THCs under the supervision of bank regulators (the Office of the Comptroller of the Currency [OCC], the FDIC and the Federal Reserve). Although acquisitions account for some of the decline, some THCs switched to BHC status, perhaps because their managers believed that the new supervisory structure reduced or eliminated the advantages of the THC classification.

Table 3, columns 4-6, present figures comparing the average percentage of 14 family residential mortgages relative to total assets for the entire sample and each portfolio over time. The figures show that the HIGH_ATL portfolio has more mortgages as a percentage of total assets over the time period studied than the $L O W \_A T L$ portfolio. The difference could affect risk measurements because, regardless of a bank's or a thrift's funding source, investors may have perceived residential mortgages as risky loans, particularly in the period surrounding and including the subprime mortgage crisis. We will, therefore, also account for differences in residential mortgage lending when forming portfolios for robustness checks.

Table 4 presents descriptive statistics on the returns on the portfolios examined, including portfolios created for robustness checks. More details on the creation of the additional portfolios are provided below. At this early stage, 


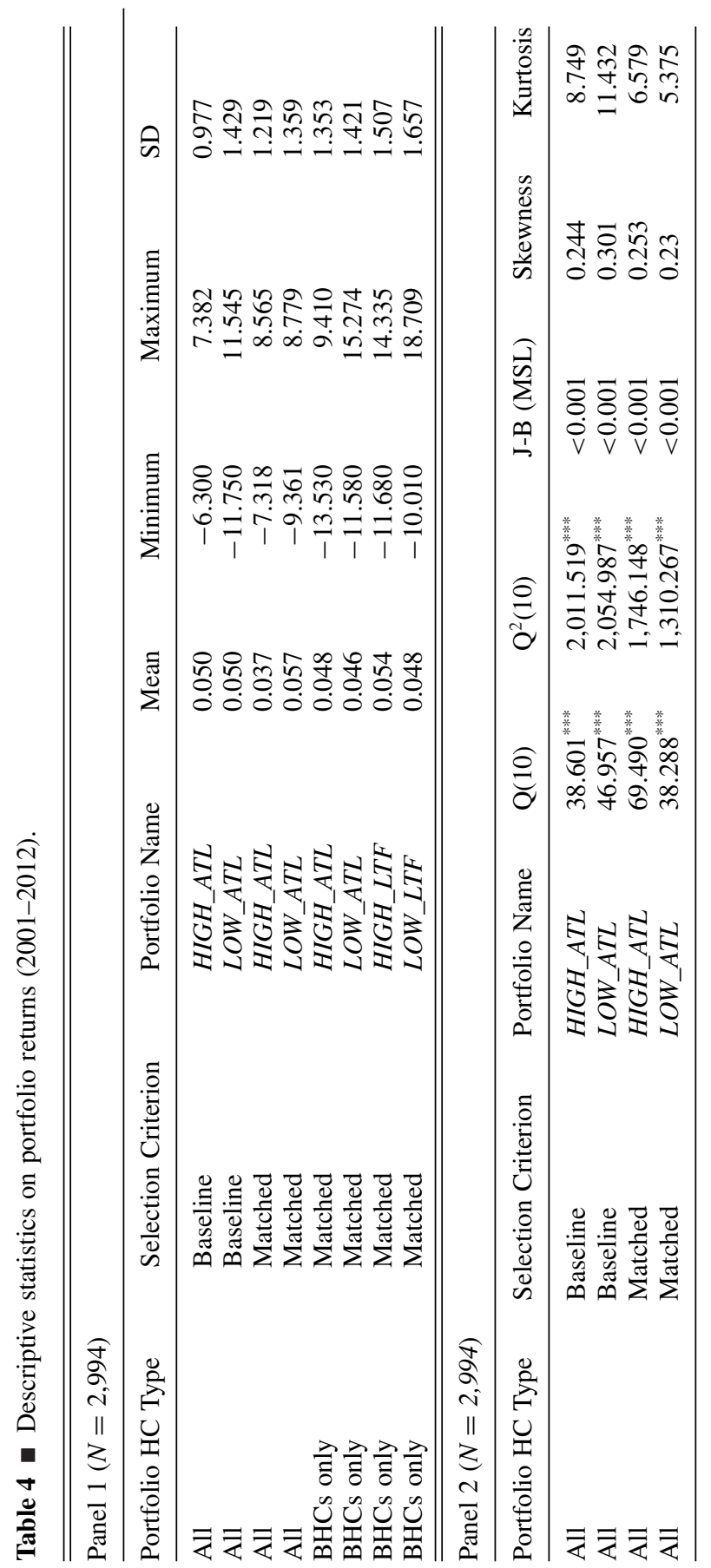




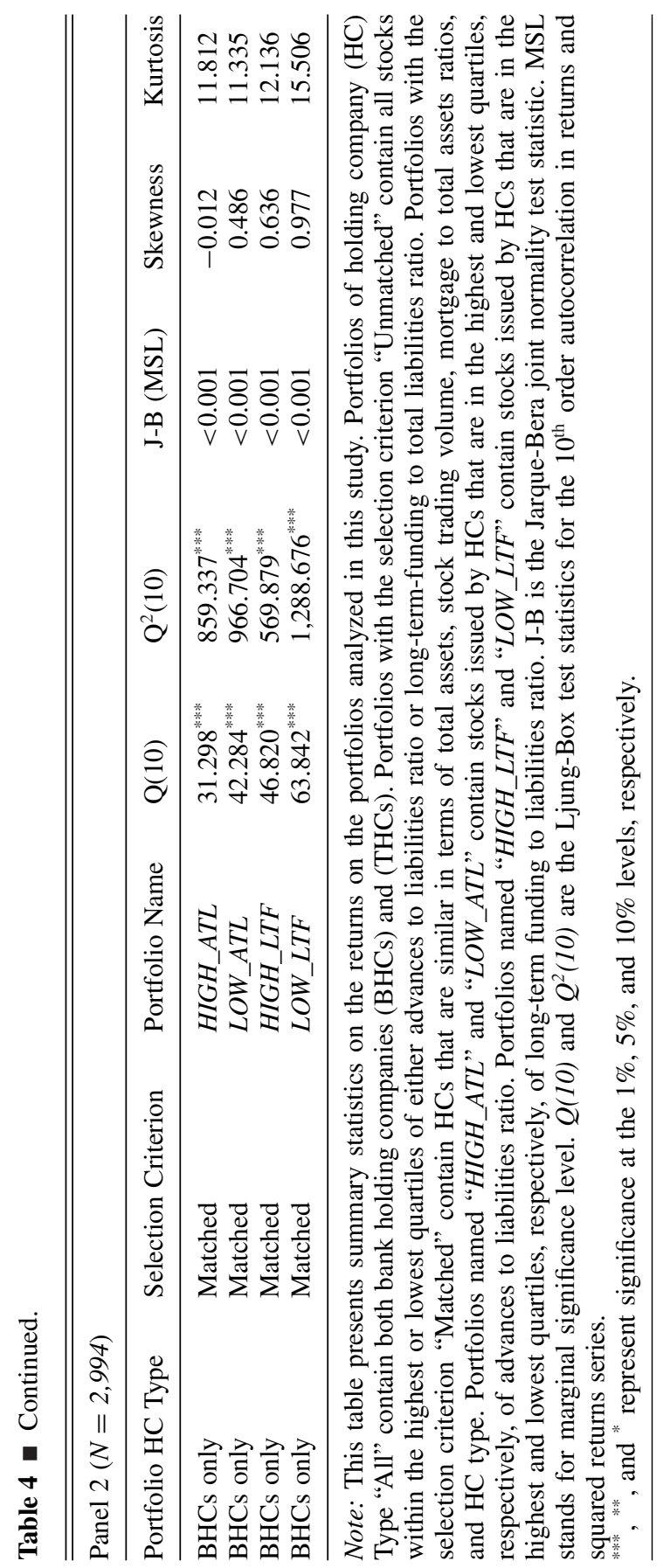


we note that Ljung-Box $Q$ statistics were computed for each portfolio's return and squared return series at 10 lags (Table 4, panel 2). These statistics lead to rejection of the null hypothesis of no autocorrelation in the return and squared return series, supporting the use of GARCH models. Jarque-Bera tests for normality, as well as calculations of skewness and kurtosis, indicate that the return series are non-normal and skewed, further supporting GARCH modeling of the return series. Dickey and Fuller's (1979) and Phillips and Perron's (1988) tests were conducted on all portfolio return series, the market return series $\left(\mathrm{RM}_{t}\right)$, and the series of one-year Treasury yields. The null hypothesis of a unit root is rejected for all series except the one-year Treasury yields. Hence, we use the differenced version of the one-year Treasury rates. The null of a unit root is rejected for the differenced yield series, supporting its use in the models.

\section{Bivariate GARCH Estimation Results}

\section{The Two-Index Model, Baseline Portfolios: Total Risk}

Table 5 presents the coefficient estimates of the two-index bivariate GARCH model of returns on the HIGH_ATL and $L O W \_A T L$ baseline portfolios. Coefficient estimates appear in panel 1, and tests of risk equality across portfolios appear in panel 2. The model is estimated for three subsample periods: precrisis (2001:Q1-2007:Q2), crisis (2007:Q3-2009:Q1), and postcrisis (2009:Q22012:Q4). Tests of the equality of total risk between the portfolios lead to the conclusion that the total risk of the HIGH_ATL portfolio is lower than that of the $L O W \_A T L$ portfolio in all three subperiods and that the risk-advantage of the former portfolio widens considerably in the crisis period. These findings support our hypothesis $\left(\mathrm{H}_{1}\right)$ proposing that the total risk of the most FHLB-reliant HCs is lower throughout the sample as well as our hypothesis $\left(\mathrm{H}_{4}\right)$ purporting that the risk advantage increases in the crisis period. The differences in mean conditional variances are small in magnitude (fractions of one percentage point). To provide an economic interpretation of these differences, we calculate the differences in mean $1 \%$ value at risk (VaR) on $\$ 1$ million invested in each portfolio. ${ }^{8}$ For the precrisis period, the difference in VaR is $\$ 764$ (less than $0.1 \%$ of the portfolio's value). This figure increases to $\$ 38,486$ (3.8\% of the portfolio's value) in the crisis period and then declines but stays above the precrisis level at $\$ 19,070$ (1.9\% of the portfolio's value) in the postcrisis period.

\footnotetext{
${ }^{8}$ The $1 \%$ VaR measures the loss that would occur on a day on which the portfolio's return is at the first percentile of the return distribution, a one-in-100 "bad day." The return distribution here is defined by the predicted mean and variance generated by the bivariate GARCH model.
} 


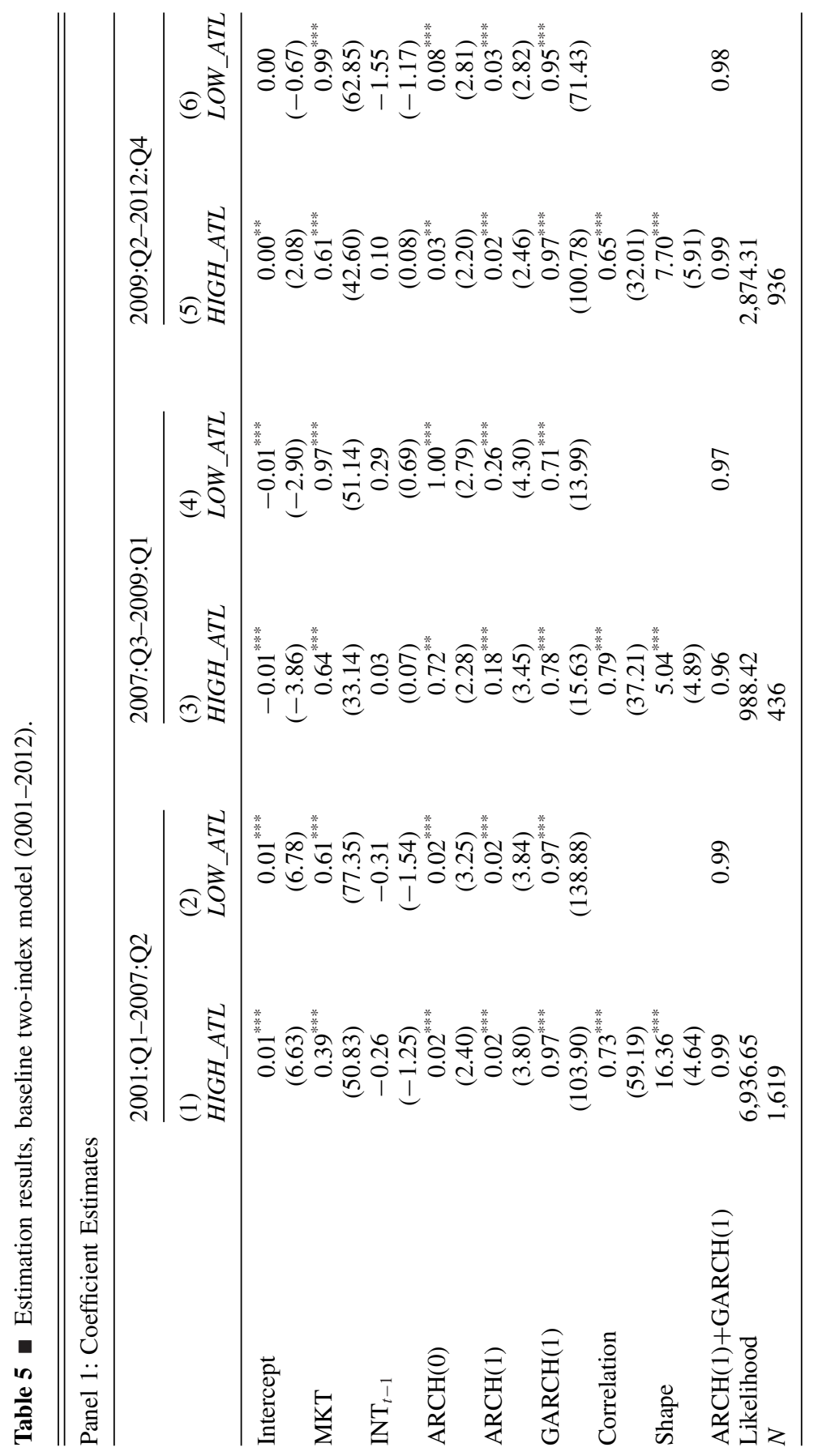




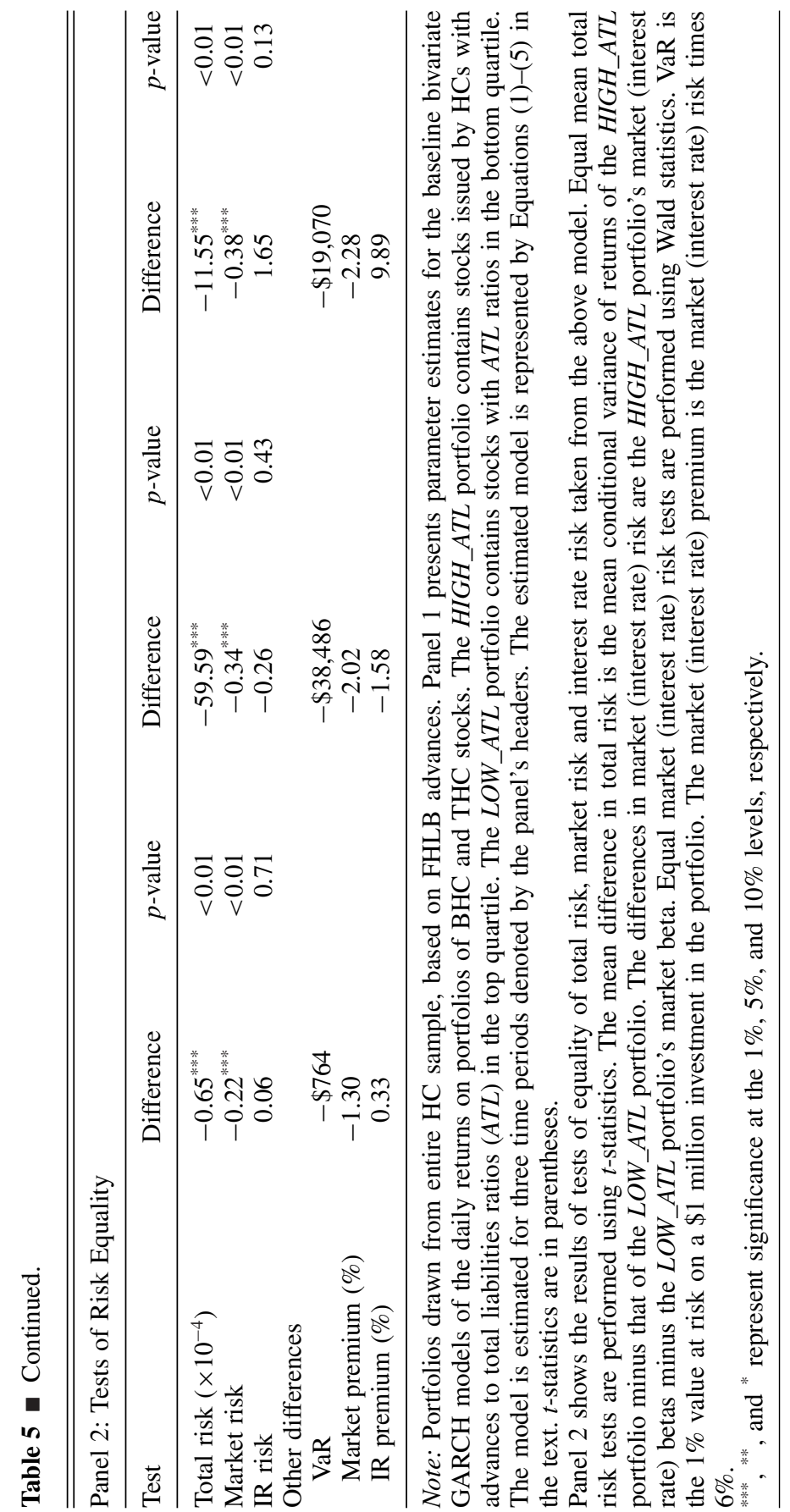




\section{The Two-Index Model, Baseline Portfolios: Market Risk}

Next, we examine and contrast the sensitivities of the two baseline portfolios to the market factor. If greater advances provide a greater cushion against market-wide shocks, the portfolio of HCs that are most reliant on advances, HIGH_ATL, should have a lower market beta. The Wald test statistics reject, at $1 \%$, the equality of market betas between the $H I G H \_A T L$ and the $L O W \_A T L$ portfolios in all three periods considered, indicating a lower risk for the former portfolio in all cases (Table 5, panel 2). Moreover, the gap between the two portfolios in terms of market beta widens from the precrisis period (0.22) to the crisis period (0.34) and widens slightly further in the post crisis period (0.38). HCs that relied most heavily on FHLB advances were less sensitive to the market factor than their counterparts relying on the advances least heavily. This evidence supports hypothesis $\mathrm{H}_{2}$, proposing that greater reliance on FHLB advances is associated with lower market risk. The increase in the gap between market betas of the two portfolios during the crisis period supports hypothesis $\mathrm{H}_{4}$, purporting a relatively smaller increase in risk during the crisis years for the HCs that used advances most heavily. The minor widening of the gap between the two baseline portfolios in the postcrisis period indicates that market fears about vulnerability of the firms were sustained, or even slightly strengthened, after the crisis was over, possibly because the chances of a bailout had declined and interest rates could not be lowered further. In this environment, firms that were most reliant on advances were perceived by market participants as being safer relative to those that were least reliant on advances. Assuming a market risk premium of $6 \%$, these gaps in market risk translate to advantages in the cost of equity capital of 130, 202 and 228 basis points for the precrisis, crisis, and postcrisis periods, respectively. These magnitudes are economically significant to an HC's investors and managers.

\section{The Two-Index Model, Baseline Portfolios: Interest Rate Risk}

Because they come in a variety of maturities, FHLB advances could help DIs match the durations of their liabilities to those of their assets-if the interest rate risk cannot be hedged in the market place at better terms. It can, thus, be argued that greater use of FHLB advances may also cushion DIs from interest rate risk if the maturities of advances are chosen appropriately to hedge that risk. If this is the case, firms relying more on FHLB advances would demonstrate less exposure to interest rate risk, as suggested by $\mathrm{H}_{3}$. However, the evidence from our model estimates indicates that neither of the baseline portfolios is significantly exposed to interest rate risk (Table 5, panel 1), and the Wald test statistics fail to reject the equality of the interest rate betas for the two portfolios in all three periods (Table 5, panel 2). 
It is possible that both groups of HCs hedged their interest rate risk without FHLB advances by using other techniques such as matching the durations of their assets and non-FHLB liabilities. It is also possible that HCs relying less on FHLB advances hedged their interest rate risk through the derivatives markets, while those relying more on FHLB advances, which are smaller and have a more limited access to such markets, hedged their interest rate risk through advances, leading to statistical insignificance of the interest rate betas for both groups. The lack of significance of interest rate betas of BHC and THC stock returns is consistent with the findings of Elyasiani and Mansur (2003), who use a similar model of BHC stock returns.

We further studied the interest rate risk of the BHC and THC portfolios by using other interest rate variables. We obtained the same results when we replaced the lagged change in the one-year Treasury yield with the lagged change in the following variables: three-month Treasury bill yields, 10-year Treasury bond yields, the difference in the 10-year and 3-month Treasury yields and the difference in the 10- and 1-year Treasury yields. The last two variables approximate the slope of the yield curve. To save space, results based on these interest rate factors are not presented here, but are available upon request. Low variation in interest rates may explain some, though not all of these results. During the crisis and post-crisis periods, short-term interest rates were close to zero, leaving little room for changes. Indeed, there were no day-to-day changes in the yields for $34 \%$ and $26 \%$ of the observations on the differenced three-month and one-year Treasuries, respectively, during those periods. However, we obtained insignificant coefficients on the differenced 10 -year Treasury yield and yield-curve slope series, but just $5-7 \%$ of those observations were zero.

Because the model estimates consistently produced insignificant coefficients on the interest rate factor, we excluded this variable and reestimated the model for the baseline portfolios. As shown in Table A1, results for the baseline portfolios are little changed. In these models the signs and significance of the comparative positions on total risk and market risk of the two portfolios remain qualitatively the same and our earlier results continue to hold. Given the insignificance of the interest rate factor, we conduct the rest of the analysis below with a single-factor model.

\section{Robustness Checks: Controlling for Confounding Characteristics}

The results discussed in the previous section may reflect differences between the two baseline portfolios with respect to several factors, including $\mathrm{HC}$ size, trading volume of stocks in the portfolio, HC type (BHC or THC) and mortgage lending activity. To begin, the sizes of the HCs in the two 
baseline portfolios could influence investors' forecasts of their cash flows in two counterbalancing directions. First, the "too-big-to-fail" (TBTF) HCs may be perceived as safer because they are more diversified, have greater access to hedging markets, and have a higher chance of being bailed out by the government if they are in distress. Consequently, these HCs would be expected to display lower total risk and lower market risk. Second, given the strong potential for a government bailout, the TBTF HCs may become bolder in taking risk. Another potential confounding factor that is related to size is the volume of trading in the stocks in each portfolio. Small HC stocks tend to have more days on which shares do not change hands than the stocks of large HCs. Such asynchronous trading tends to generate observations with zero returns (Table 2, columns 9 and 10), which could misleadingly reduce the portfolio returns' variation around their mean and reduce their comovement with the market and interest rate factors (Campbell, Lo and MacKinlay 1996).

In addition, as mentioned earlier, THCs comprise a substantially greater share of stocks in the baseline HIGH_ATL portfolios than in the corresponding $L O W \_A T L$ portfolios. The primary regulator of thrifts and THCs, the OTS, was found by government watchdogs, politicians, and the news media to have made serious errors in its regulation of large thrifts and their corresponding THCs such as IndyMac, Washington Mutual and Countrywide (Applebaum and Nakashima 2008; Treasury Department 2010). In response, the DoddFrank Act mandated the closing of the OTS and transferred its responsibilities to the OCC, FDIC and the Federal Reserve. If THCs were riskier than BHCs in the time period examined, due to lax regulation and weak regulatory monitoring, then we could expect them to pull up the risk of the HIGH_ATL portfolio, offsetting some of the risk reduction effects of the FHLB advances. In this scenario, the risk advantages of the HIGH_ATL portfolio are underestimated because of the higher frequency of presence of THCs in this portfolio compared to the $L O W \_A T L$ portfolio.

The most FHLB-reliant institutions (in $H I G H \_A T L$ ) tend to hold more mortgages as part of their portfolios than the least FHLB-reliant (in $L O W \_A T L$. See Table 3, columns 5 and 6). It is true that money is fungible, and advances do not necessarily lead to increased residential lending at commercial banks on the whole (Frame, Hancock and Passmore, 2012). FHLBs, however, are historically associated with residential lending. For thrifts, which operate under regulations that encourage residential lending, FHLB advances may tend to fund residential real estate loans more than other types of lending. This means that during the crisis, which centered on residential real estate, investors could have perceived greater risk in the HCs in HIGH_ATL 
because of their high exposure to real estate, rather than the source of their funding.

To address these sometimes conflicting factors-size, trading volume, HC type and differences in residential mortgage lending, we used a propensity score matching procedure to form additional portfolios from subsets of the sample so that the stocks in each portfolio more closely resembled each other along these dimensions. (Details on the portfolio formation process and its results are in Appendix 2.) We call the portfolios that result from this process "matched" portfolios. Each stock in the $H I G H \_A T L$ portfolio has a corresponding stock in the $L O W \_A T L$ portfolio with similar total assets, trading volume and mortgage-to-total-assets ratio. ${ }^{9}$ To the degree the matching procedure allows, the HC's types (BHC or THC) are also the same. The differences between the portfolios with respect to these factors are considerably narrower than the differences among the baseline portfolios analyzed in the previous section (see Tables A2 and A3). This reduces the chances that our findings are driven by these confounding factors. We note that the matching process does not narrow the difference in the percentage of THCs as much as it does the other factors. To address this issue, we later analyze the returns on another set of matched portfolios that include BHCs only.

The matched-portfolio results, reported in Table 6, indicate that size, trading volume, $\mathrm{HC}$ type and residential mortgage lending did not affect the direction of the findings regarding total risk in the pre- and postcrisis periods, although it did affect them during the crisis period. To elaborate, for the matched portfolios, as with the baseline portfolios, we find that greater FHLB advances are associated with reduced total risk in the pre- and postcrisis periods, but with greater, rather than smaller, total risk during the crisis period. In terms of magnitude, in the pre- and postcrisis periods, the matched HIGH_ATL portfolio, on average, has mean VaR figures of $\$ 12,829$ and $\$ 31,586$, respectively, lower than the corresponding matched $L O W \_A T L$ portfolio, for a $\$ 1$ million investment in each of the two portfolios. The corresponding figures for the baseline portfolio are $\$ 764$ and $\$ 19,070$. During the crisis period, however, we observe a significant relative increase in total risk for the HIGH_ATL portfolio vis-à-vis the matched $L O W \_A T L$ portfolio. In this period, the $H I G H \_A T L$ portfolio has a mean $\mathrm{VaR}$ on a $\$ 1$ million portfolio that is $\$ 4,981$ greater than its matched $L O W \_A T L$ counterpart. It is notable that HCs in both the high and low advances quartiles relied more heavily on FHLB advances during the crisis period, but investors seem to have elevated their assessments of risk to a greater extent for the HCs that relied on FHLBs the most. This finding

${ }^{9}$ We thank an anonymous referee for this suggestion. 


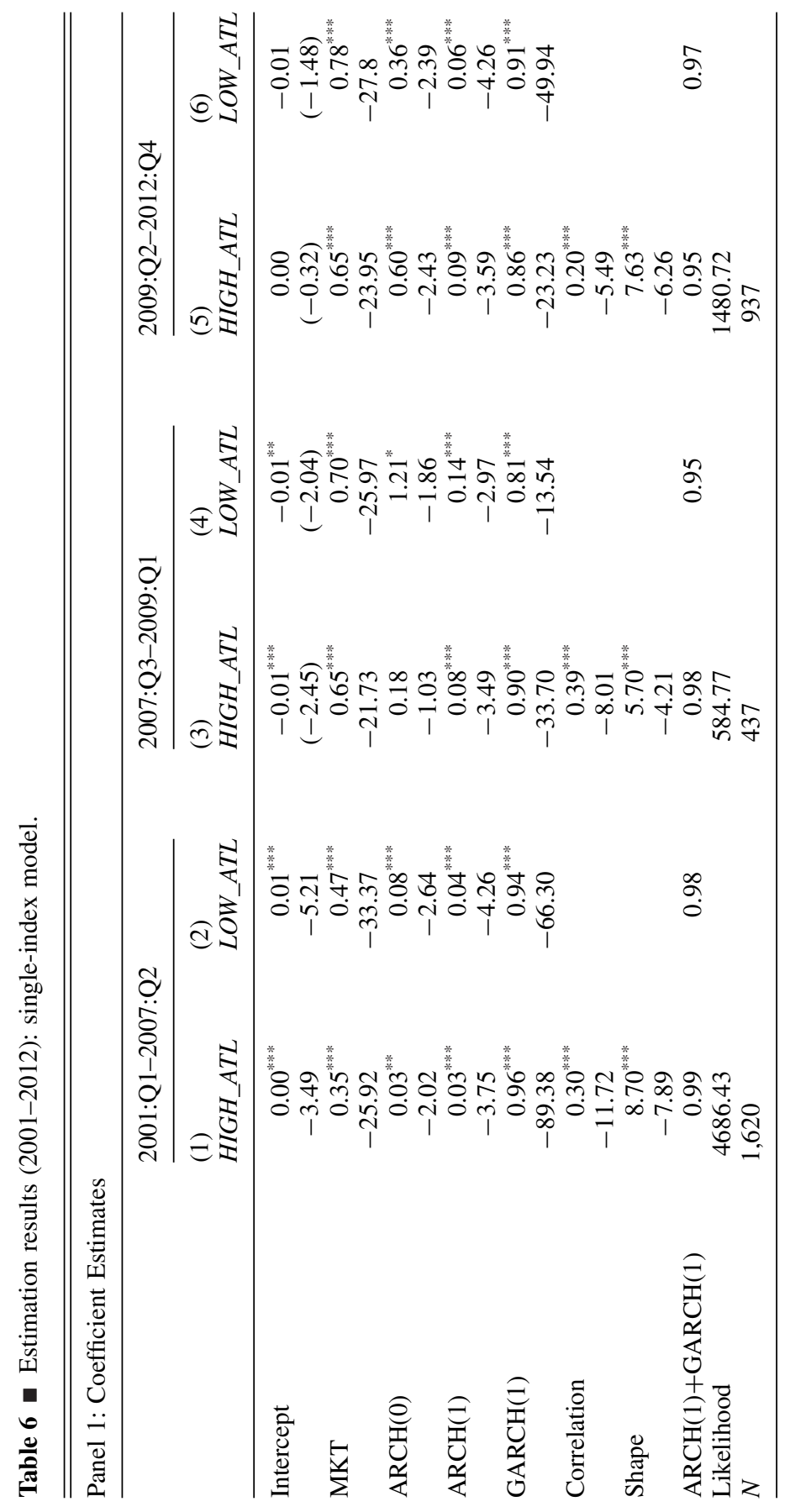




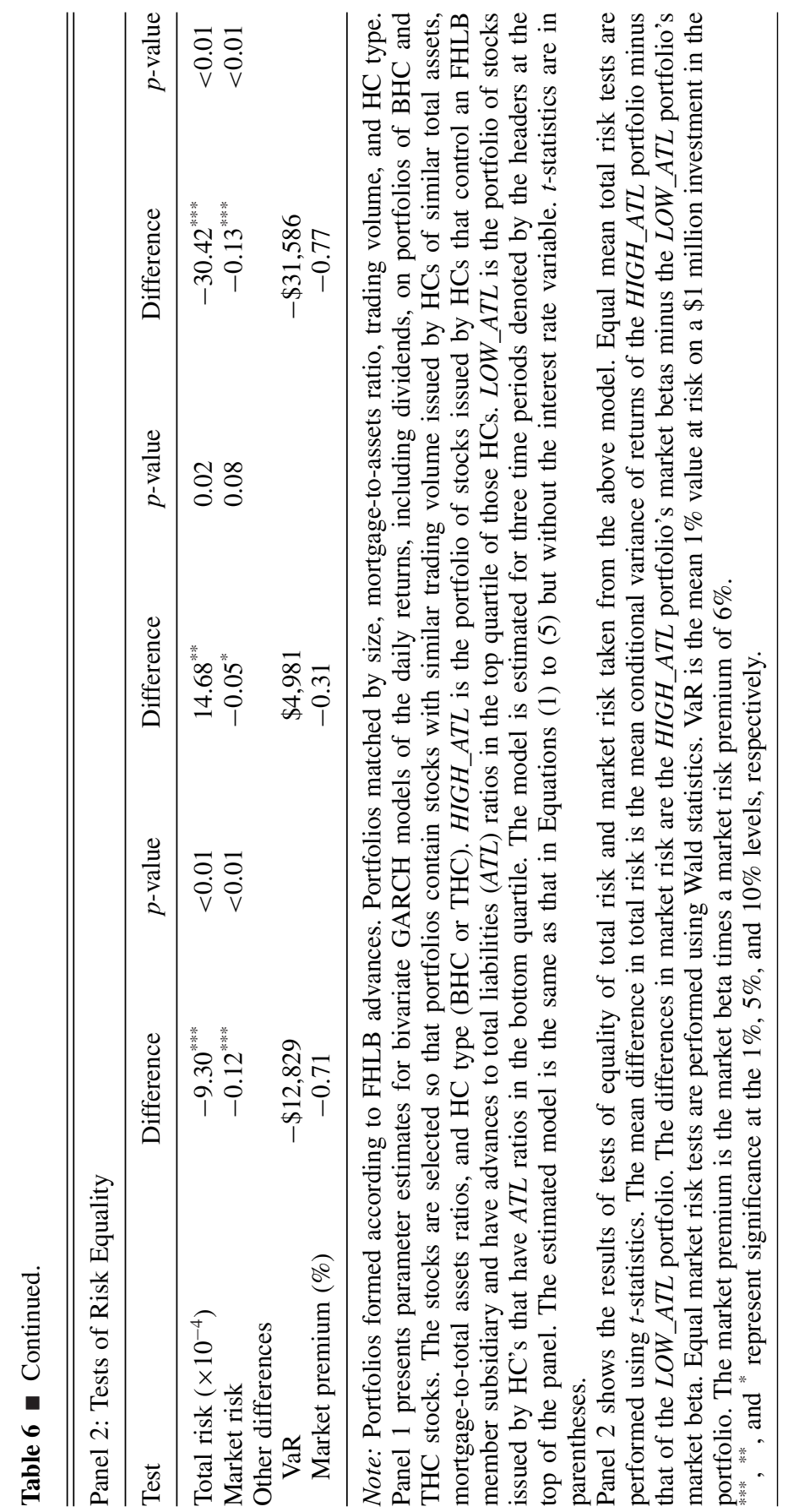


is an indication that investors considered the heavy reliance on advances by HCs in the HIGH_ATL portfolio an act of desperation. Specifically, they may have believed that these HCs used more FHLB advances because they lacked alternatives and were in or near distressed conditions. As Ashcraft, Bech and Frame (2010) write, markets for short-term borrowing were frozen during the crisis, and six of the 10 leading recipients of FHLB advances during this period either later failed, were acquired, or received "exceptional assistance" from the U.S. government.

The gaps in market risk between the matched portfolios with the highest and lowest FHLB advances are not as great as in the baseline model, suggesting that some of the differences observed between the two baseline portfolios were due to the confounding factors for which the matching procedure controls. Converted to cost of funds with a market risk premium of $6 \%$, the advantages of the HIGH_ATL portfolio compared to the $L O W \_A D V$ matched portfolio are 71,31 and 77 basis points in the precrisis, crisis, and postcrisis periods, respectively, compared to 130,202 and 228 basis points found earlier from the baseline models.

Taken together, a large increase in the HIGH_ATL portfolio's total risk relative to that of $L O W_{-} A T L$, and a narrowing of the gap in market risk between the two portfolios imply a relative increase in the idiosyncratic risk of the HCs in $H I G H \_A T L$ during the financial crisis. This difference in idiosyncratic risk arises after controlling for a number of confounding factors, including reliance on mortgages. We interpret this as evidence that investors believed there was something particularly risky about firms that relied most heavily on FHLB advances, suggesting they thought the FHLBs were directing the greatest bulk of their emergency funding to prop up the highly risky HCs.

\section{Robustness Checks: Matched Portfolios of BHCs Only}

When we use the propensity score procedure to match the stocks in the portfolio, the difference between the HIGH_ATL and $L O W \_A T L$ portfolios in terms of THC percentage narrows, but a significant gap remains. In the baseline portfolios, the $H I G H \_A T L$ on average has 31 percentage points more THCs, whereas in the matched portfolios, the HIGH_ATL on average has 22.1 percentage points more. We examine this issue further by excluding THCs from the sample and forming $H I G H \_A T L$ and $L O W \_A T L$ portfolios of size- and volume-matched BHCs.

For portfolios of BHCs matched by size, trading volume and mortgage to assets ratio, we find that the gap in total risk is qualitatively similar to 
the matched portfolios including both BHCs and THCs discussed above (Table 7, panel 2). Specifically, when THCs are excluded from the portfolio, there is still a negative association between total risk and reliance on FHLB advances before and after the crisis, but a positive and significant association during the crisis. For market risk, too, the advantage of $H I G H \_A T L$ over the $L O W \_A T L$ portfolio remains in effect during all periods. These findings provide evidence that the results for the matched portfolios drawn based on the entire sample of HCs are not altered in a major way by the presence of the THCs. Given that the HCs examined are relatively small (averaging less than $\$ 10$ billion in total assets), our result for the crisis period indicates that, in spite of the well-known troubles at Washington Mutual, Countrywide, and IndyMac, investors did not perceive the "rank-and-file" THCs that relied heavily on FHLB advances as riskier than similar-sized BHCs.

Robustness Checks: Matched-Portfolios of BHCs Only, Based on Long-Term Funding

Our data indicate that HCs that rely the most on advances also rely proportionally more on long-term advances than short-term advances. The opposite is true for the least advance-reliant HCs. Table 8 shows the share of advances that mature in one year or longer for all BHCs in the sample, as well as those in the highest and lowest quartiles of $A T L$. For the highest ATL quartile, longterm advances comprise between $62.2 \%$ and $78.6 \%$ of their total advances. For the lowest ATL quartile, long-term advances make up between $25.3 \%$ and $47.8 \%$ of total advances. In other words, the scale and the maturity of advances are complements, rather than substitutes; they move in the same direction. If long-term funding mitigates risk, then the results based on baseline models may be driven in part by the long-term nature of the advances drawn by the HCs in the top quartile of $A T L$, rather than advances per se.

We, therefore, form two additional portfolios with BHC stocks in the highest and lowest quartile of the ratio of long-term funding to total liabilities (LTF), $H I G H \_L T F$ and $L O W \_L T F$. THCs are excluded from the sample because data on the time to maturity of their liabilities became available only in 2011. As with the previously discussed matched portfolios, the stocks in the portfolios are also matched according to total assets, trading volume and mortgageto-assets ratio. We calculate the LTF values by adding each DI's reported advances, time deposits, subordinated debt, debentures, and other borrowings that mature in one year or more and dividing the sum over total liabilities. The exact weighted average maturity of the advances and other long-term funds cannot be measured because data on liabilities are available only by maturity buckets rather than exact maturities. 


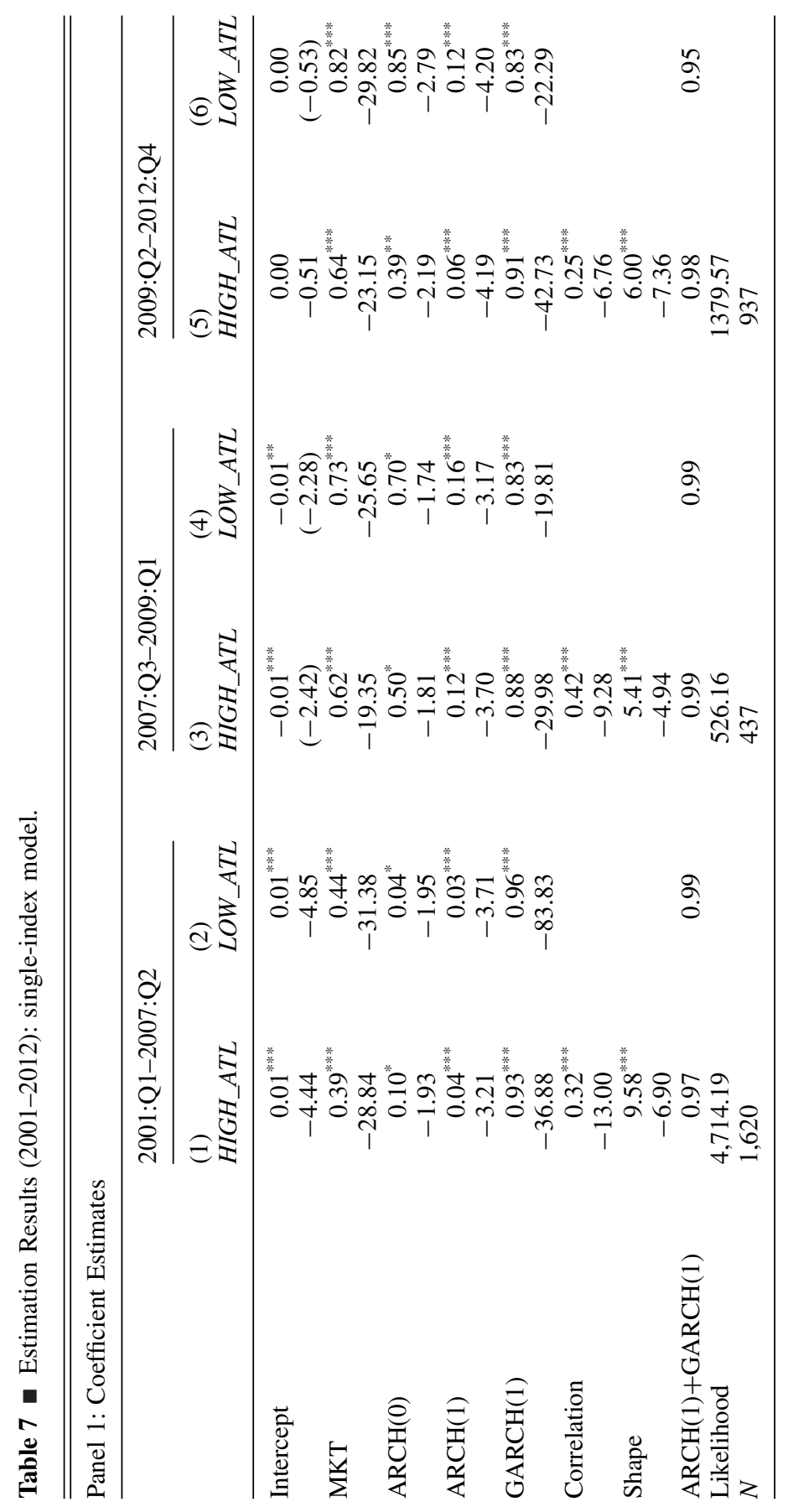




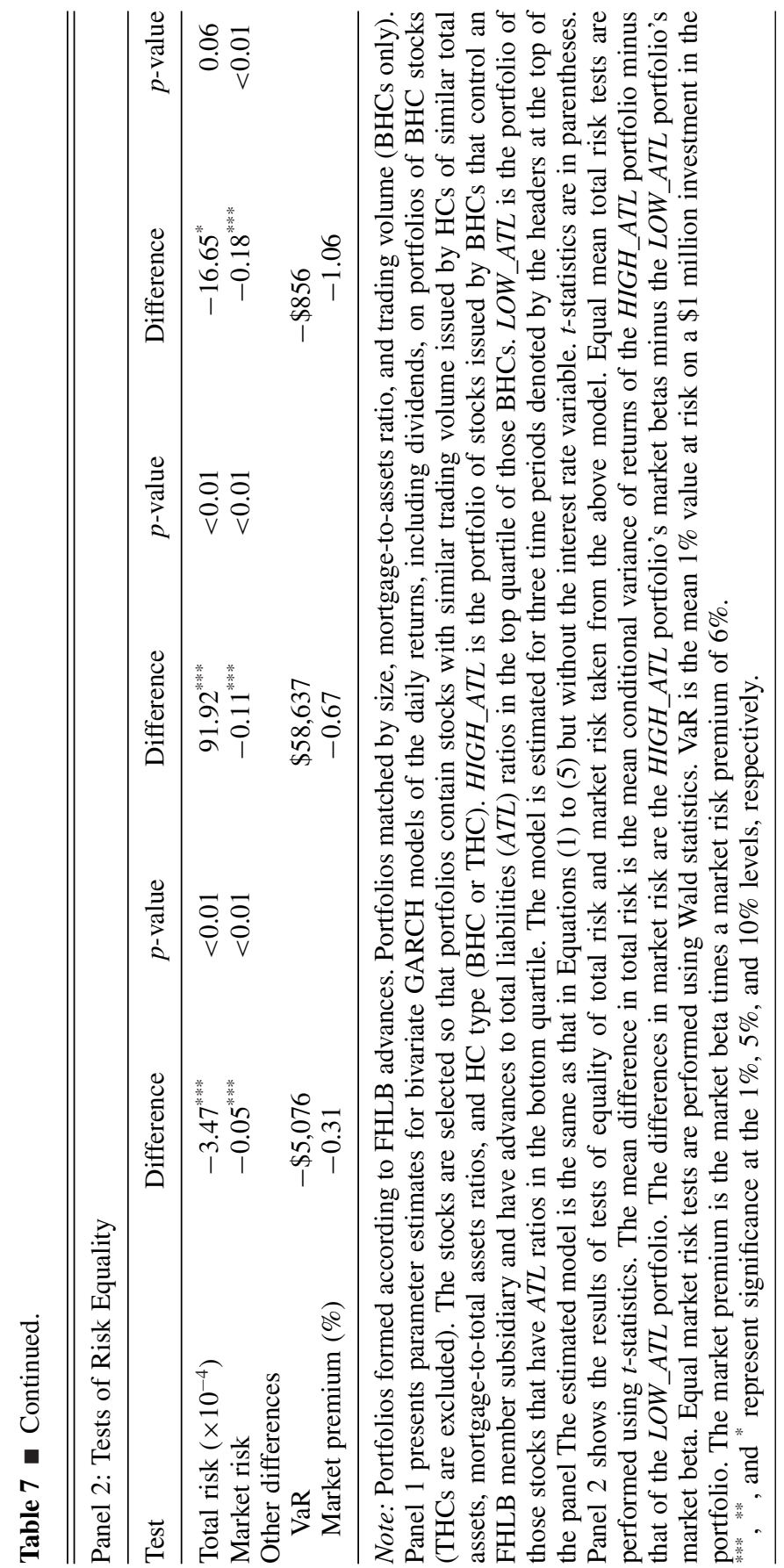


Table 8 a Bank holding company use of long-term advances by year (2001-2012).

\begin{tabular}{llll}
\hline \hline & \multicolumn{3}{l}{ Percentage of all Advances that Mature in One Year or Longer } \\
\cline { 2 - 4 } & $(1)$ & $(2)$ & $(3)$ \\
Year & Entire & Highest ATL & $\begin{array}{l}\text { Lowest ATL } \\
\text { Quartile }\end{array}$ \\
\hline 2001 & Sample & 76.4 & 25.3 \\
2002 & 60.2 & 75.9 & 35.5 \\
2003 & 63.6 & 73.4 & 37.1 \\
2004 & 63.2 & 68.8 & 37.0 \\
2005 & 59.9 & 63.0 & 39.4 \\
2006 & 56.9 & 62.2 & 38.6 \\
2007 & 57.1 & 68.9 & 45.1 \\
2008 & 59.2 & 71.6 & 47.8 \\
2009 & 62.6 & 72.9 & 45.0 \\
2010 & 63.1 & 76.4 & 38.5 \\
2011 & 62.9 & 78.6 & 33.1 \\
2012 & 64.8 & 69.7 & 25.5 \\
\hline
\end{tabular}

Note: The above table presents statistics on the percentage of advances that mature in one year or longer (long-term advances) as reported by bank holding companies (BHCs) in the sample. The percentage is found by dividing the sum of the HCs' subsidiaries' long-term advances by the subsidiaries' total advances. The figures are calculated from quarterly data from Call Reports filed by the BHCs subsidiary depository institutions. The data in the columns labeled "Highest ATL Quartile" and "Lowest ATL Quartile" are for BHCs in the highest and lowest quartiles, respectively, of advances to liabilities ratio.

As we found with the portfolios of BHCs formed according to reliance on FHLB advances, heavier reliance on long-term funding as a whole is associated with less total risk in the pre-crisis period (Table 9). Although we cannot statistically test the differences in the total risk gaps among the sets of portfolios considered, we see that the total risk gap is smaller in the precrisis period for the portfolios formed according to long-term funds than for the portfolios formed according to advances (Table 6). This suggests that longterm funding cannot be the sole contributor to the risk difference between the two portfolios and reliance on advances does per se lower risk. This result again supports our hypothesis $\mathrm{H}_{1}$ (greater reliance on FHLB advances is associated with lower total risk) for the pre-crisis period. In addition, heavier reliance on long-term funding is found to be associated with lower total risk during the crisis period, while it is associated with greater total risk for the matched portfolio. Heavier reliance on long-term funding is associated with greater total risk during the post-crisis period while greater reliance on advances is associated with lower total risk than for the baseline and matched portfolios. This further strengthens our results on the risk-reduction effect 


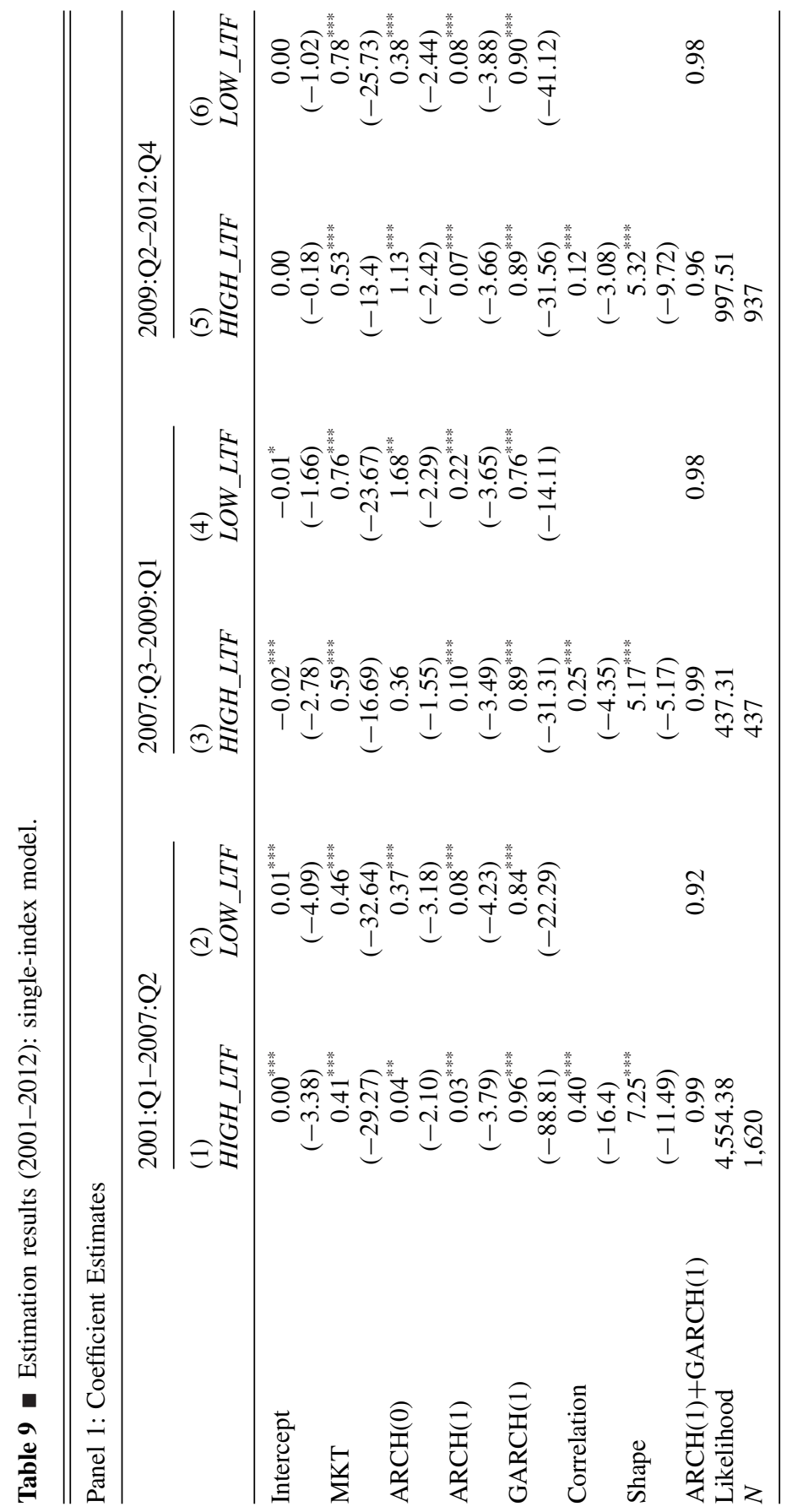




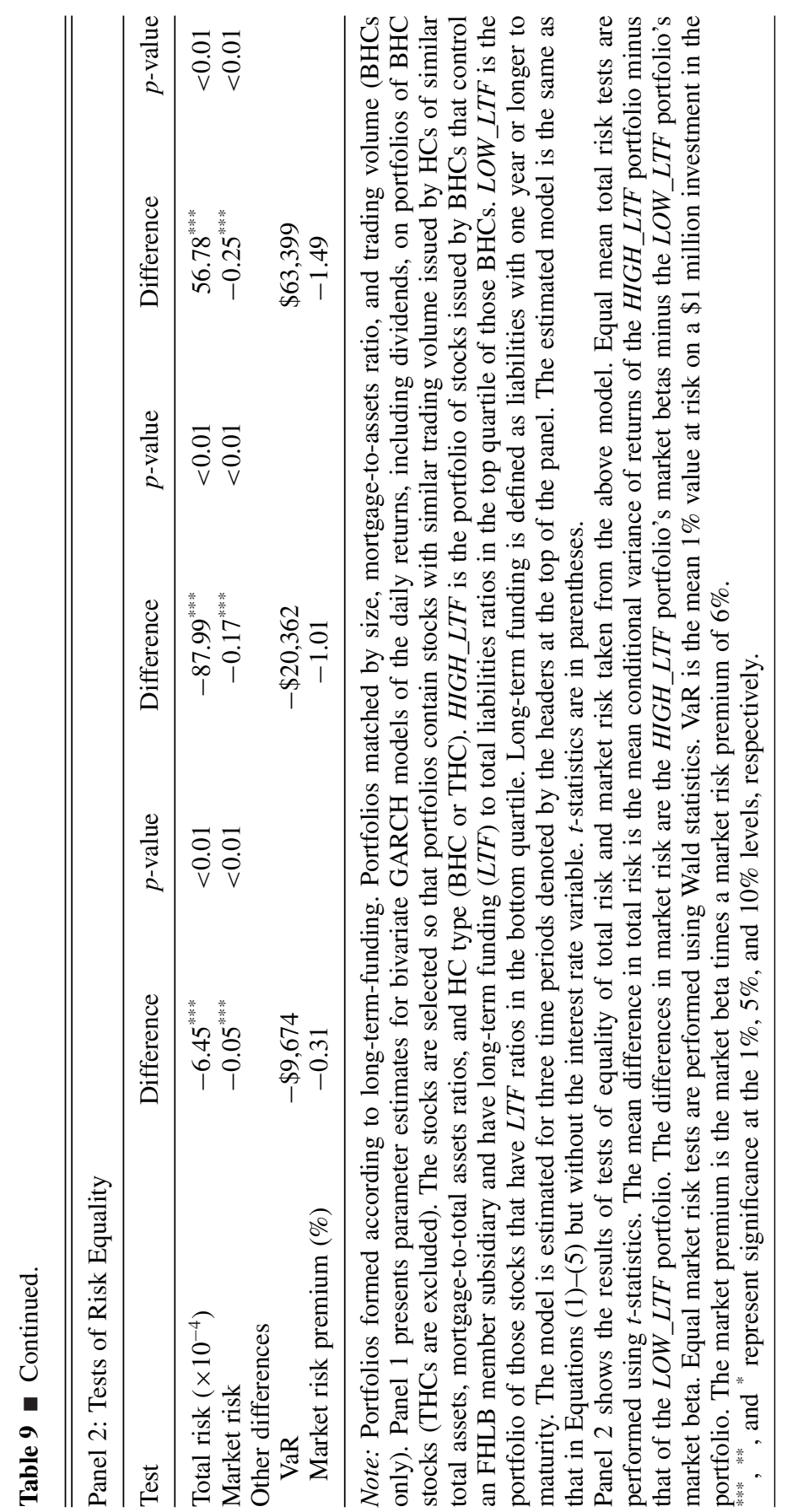


of advances. The average VaR differences for portfolios based on long-term funding are, in chronological order, $-\$ 9,674,-\$ 20,362$ and $\$ 63,399$, compared to $-\$ 12,829, \$ 4,981$ and $-\$ 31,586$ for the matched BHC portfolios based on FHLB advances. We also see a different pattern in market risk for the portfolios of BHCs formed according to long-term funding. In contrast with matched $H I G H \_A T L$ portfolios that fail to show an advantage or disadvantage in market risk, the $H I G H \_L T F$ portfolio does show an advantage in market risk during the crisis period. Based on our test results and the differential patterns of effects associated with FHLB advances and long-term funds, we conclude that our earlier results on the matched portfolios formed according to reliance on FHLB advances are not largely driven by long-term funding effects.

\section{Conclusion}

After more than 80 years, FHLBs remain a significant part of the U.S. mortgage market. Their importance was exhibited again during the financial crisis of 2007-2009 when they provided billions of dollars above their normal levels of funding to U.S. depository institutions. An analysis of the volatility of $\mathrm{HC}$ stock returns, rather than accounting ratios, to assess $\mathrm{HC}$ risk provides a new way to examine the impact of FHLBs on U.S. depository institutions in the periods leading up to, during, and after the financial crisis. We find that when we look at the pool of all stock-issuing BHCs and THCs that control FHLB member depository institutions, greater reliance on advances is associated with less risk. Between 2001 and 2012, a portfolio of the most FHLB-reliant HCs consistently exhibited lower total and market risks than a portfolio of HCs that were least reliant on FHLBs, with total risk measured by the conditional variance of portfolio returns, and market risk measured by the market beta. We also find that, consistent with some of the existing literature, interest rate risk is not an important determinant of the HC stock returns in our sample. We, thus, find no advantage in interest rate risk management for HCs that rely most heavily on advances.

We conduct several tests of robustness of our findings. When we control for differences in $\mathrm{HC}$ size, stock trading frequency, $\mathrm{HC}$ type (BHC or THC), and mortgage-to-assets ratio, we find that while the most FHLB-reliant HCs do retain their market risk advantage over the 2001-2012 period and their total risk advantage in the pre- and post-crisis periods, they exhibit higher total risk during the crisis. It appears that the HCs relying on FHLB advances more heavily were perceived by the market participants as being exposed to significantly more idiosyncratic risk during the crisis than those that made little 
use of FHLB funds. We also find that our results are robust to the exclusion of THCs, believed by many to have been subject to weaker regulation in the years leading up to the crisis. More specifically, a subsample of only BHCs that controls for size and trading volume effects exhibits similar risk advantages for the BHCs most reliant on FHLB advances to that observed for the composite portfolios of BHCs and THCs. Finally, our results are robust with respect to the long-term maturity of the advances. Based on model estimates that employ returns on portfolios formed according to long-term funding, we find that the longer term to maturity of advances weakens but does not fully capture our results on advances.

While these findings do not provide an accounting of the overall welfare costs or benefits of the FHLB system, they do provide some insights into some other matters of policy debate. In particular, our main finding-heavy HC reliance on FHLB advances is associated with less total risk before and after the crisis but more risk during the crisis-can be interpreted in two ways. One is that FHLBs acted, according to design, to provide liquidity to the mortgage industry in a time of need. The other interpretation is that the FHLBs acted to prop up relatively risky HCs. This latter action, in turn, signaled a state of distress for these and other FHLB-reliant depository institutions, in the eyes of the investors, reflecting the moral hazard created by the government backing of the FHLB system. Our findings with respect to the increase in idiosyncratic risk for the most FHL-reliant HCs during the subprime mortgage crisis gives greater weight to the second interpretation. Finally, although the OTS was criticized for laxity in its supervision of large thrifts and THCs such as IndyMac, Washington Mutual and Countrywide, at the level of smaller, publicly-traded HCs and subsidiaries, our results indicate that oversight by OTS may not have been significantly different from other regulators-at least in terms of risk perceived by the market.

Elyas Elyasiani is a Senior Cochran Research Fellow at the Fox School of Business and Management, Temple University, a Fellow at the Wharton Financial Institution Center, University of Pennsylvania and a Visiting Professor and Dean's Fellow at the Jerusalem School of Business, Hebrew University, Israel. He would like to thank Temple University for Summer Research Grants during summers 2013, 2014 and 2016. Earlier versions of the paper were presented at the Financial Management Association (FMA) annual meeting 2011 in Denver, Co, and the Eastern Finance Association (EFA) annual meeting 2011 in Savannah, GA. The authors would like to thank Scott Frame, Yan Li, Iqbal Mansur, Ajay Palvia, Jonathan Scott, Larry Wall and Hakan Yilmazkuday for reading and commenting on various drafts of this article, and, in particular, two anonymous referees of the Journal for thorough reviews 
and helpful suggestions that have improved the quality of the paper. For help obtaining the data, we thank Scott Smith, Gary Ternullo and the staff of the Federal Housing Finance Agency and Jim Caton and Keith Lester, formerly of the OTS. Errors are our responsibility.

\section{References}

Akella, S.R. and S.-J. Chen. 1990. Interest Rate Sensitivity of Bank Stock Returns: Specification Effects and Structural Changes. Journal of Financial Research 13(2): $147-154$

Applebaum, B. and E. Nakashima. 2008. Regulator Let IndyMac Falsify Report. The Washington Post. December 23.

Ashcraft, A. 2008. Are Bank Holding Companies a Source of Strength to their Subsidiaries? Journal of Money, Credit and Banking 40(2-3): 273294.

- M.L. Bech and W.S. Frame. 2010. The Federal Home Loan Bank System: The Lender of Next-to-Last Resort? Journal of Money, Credit and Banking 42(4): 551-583.

Bauwens, L., S. Laurent and J.V. Rombouts. 2006. Multivariate GARCH models: A survey. Journal of Applied Econometrics 21(1): 79-109.

Bennett, R.L., M.D. Vaughan and T.J. Yeager. 2005. Should the FDIC Worry about the FHLB: The Impact of Federal Home Loan Bank Advances on the Bank Insurance Fund. Working Paper, FDIC.

Berndt, E.K., B.H. Hall, R.E. Hall and J.A. Hausman. 1974. Estimation and Inference in Nonlinear Structural Models. Annals of Economic and Social Measurement 3(4): 103-116.

Bessler, W. and P. Kurmann. 2014. Bank Risk Factors and Changing Risk Exposures: Capital Market Evidence Before and During the Financial Crisis. Journal of Financial Stability 13: 151-166.

Bollerslev, T. 1990. Modelling the Coherence in Short-run Nominal Exchange Rates: A Multivariate Generalized ARCH model. Review of Economics and Statistics 72(3): 498-505.

Browne, M.J., J.C. Carson and R.E. Hoyt. 1999. Economic and Market Predictors of Insolvencies in the Life-Health Insurance Industry. Journal of Risk and Insurance 66(4): 643-659.

Campbell, J.Y, A.W. Lo and A.C. MacKinlay. 1996. The Econometrics of Financial Markets. Princeton, N.J.: Princeton University Press.

Carson, J.C., E. Elyasiani and I. Mansur. 2008. Market Risk, Interest Rate Risk, and Interdependencies in Insurer Stock Returns: A System-GARCH Model, Journal of Risk and Insurance 75(4): 873-891.

Dickey, D.A. and W.A. Fuller. 1979. Distribution of the Estimators for Autoregressive Time Series With a Unit Root. Journal of the American Statistical Association 74: 427-431.

Elyasiani, E. and I. Mansur. 2003. International Spillover of Risk and Return Among Major Banking Institutions: A Bivariate GARCH Model. Journal of Accounting, Auditing and Finance 18: 303-330.

, and M.S. Pagano. 2007. Convergence and Risk-Return Linkages Across Financial Services Firms. Journal of Banking and Finance 31: $1167-1190$. 
Financial
Institutions' J.L. Wetmore. 2010. Real-Estate Risk Effects on Analysis. Journal of Real Estate Finance and Economics 40(1): 89-107.

Engle, R.F. 2001. GARCH 101: The Use of ARCH/GARCH Models in Applied Econometrics. The Journal of Economic Perspectives 15(4): 157168.

FHLB Office of Finance. 2015. Federal Home Loan Bank System Lending and Collateral Q\&A (November 13, 2015). Available at http://www.fhlbof.com/ofweb_userWeb/resources/lendingqanda.pdf

Federal Housing Finance Agency. 2015. Quarterly Performance Report of the Housing GSEs. Second Quarter. Washington, D.C. Available at http://www.fhfa. gov/AboutUs/Reports/ReportDocuments/20152Q_QuarterlyPerformance_Housing GSEs.pdf

Flannery, M.J. and W.S. Frame. 2006. The Federal Home Loan Bank system: The "other" housing GSE. Federal Reserve Bank of Atlanta Economic Review 91(3): 3354.

Frame, W.S., D. Hancock and W. Passmore. 2012. Federal Home Loan Bank Advances and Commercial Bank Portfolio Composition. Journal of Money, Credit and Banking 44(4): 661-684.

Gorton, G. 2010. Questions and answers about the financial crisis. National Bureau of Economic Research Working Paper Series 15787.

Hoffman, S. 2001. Politics and Banking: Ideas, Public Policy, and the Creation of Financial Institutions. Baltimore: Johns Hopkins University Press.

Phillips, P.C.B. and P. Perron. 1988. Testing for a Unit Root in Time Series Regression. Biometrika 75(2): 335-346.

Scott, J.A. and S.E. Hein. 2009. The Federal Home Loan Banks and Commercial Bank Risk Taking: An Overstated Moral Hazard? Working Paper, Temple University. Available at http://dx.doi.org/10.2139/ssrn. 1175366

and - 2011. The Federal Home Loan Banks: A Government Sponsored Enterprise That Avoided Conservatorship. Journal of Applied Finance 21(1): 44-61.

Song, F.M. 1994. A two-factor ARCH model for deposit-institution stock returns. Journal of Money, Credit and Banking 26(2): 323-340.

Stojanovic, D., M.D. Vaughan and T.J. Yeager. 2008. Do Federal Home Loan Bank membership and advances increase bank risk-taking? Journal of Banking and Finance 32(5): 680-698.

Treasury Department, Office of the Inspector General. 2010. Evaluation of Federal Regulatory Oversight of Washington Mutual Bank. Report No. EVAL10-002. Washington D.C. Available at https://www.fdicig.gov/reports10/10-002EV. pdf

Wall Street Reform and Consumer Protection Act, U.S. Code 12, Chapter 53. 2010. https://www.law.cornell.edu/uscode/text/12/chapter-53 (accessed May 26, 2016).

\section{Appendix A: Baseline Model Estimate Without Interest Rate Variable}




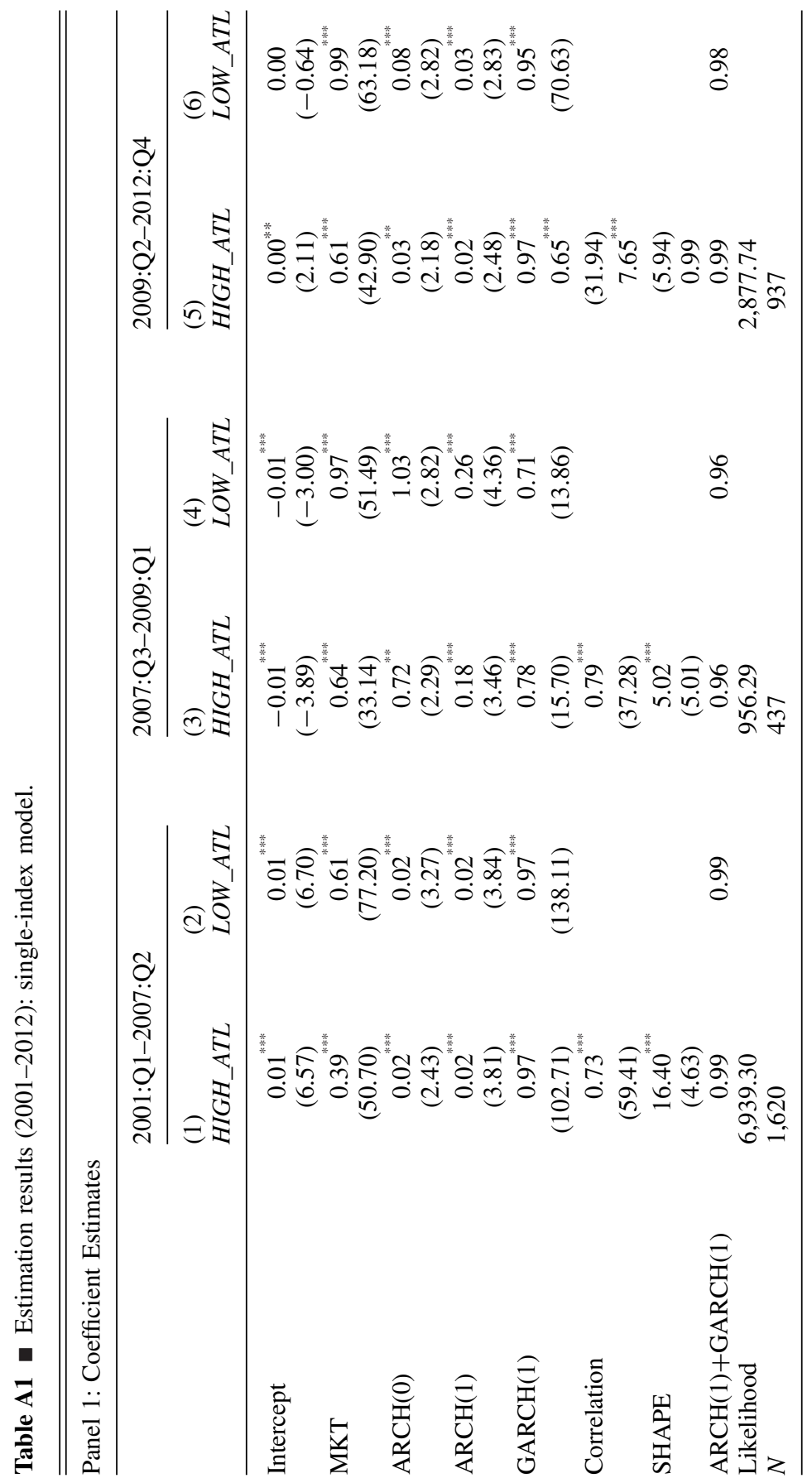




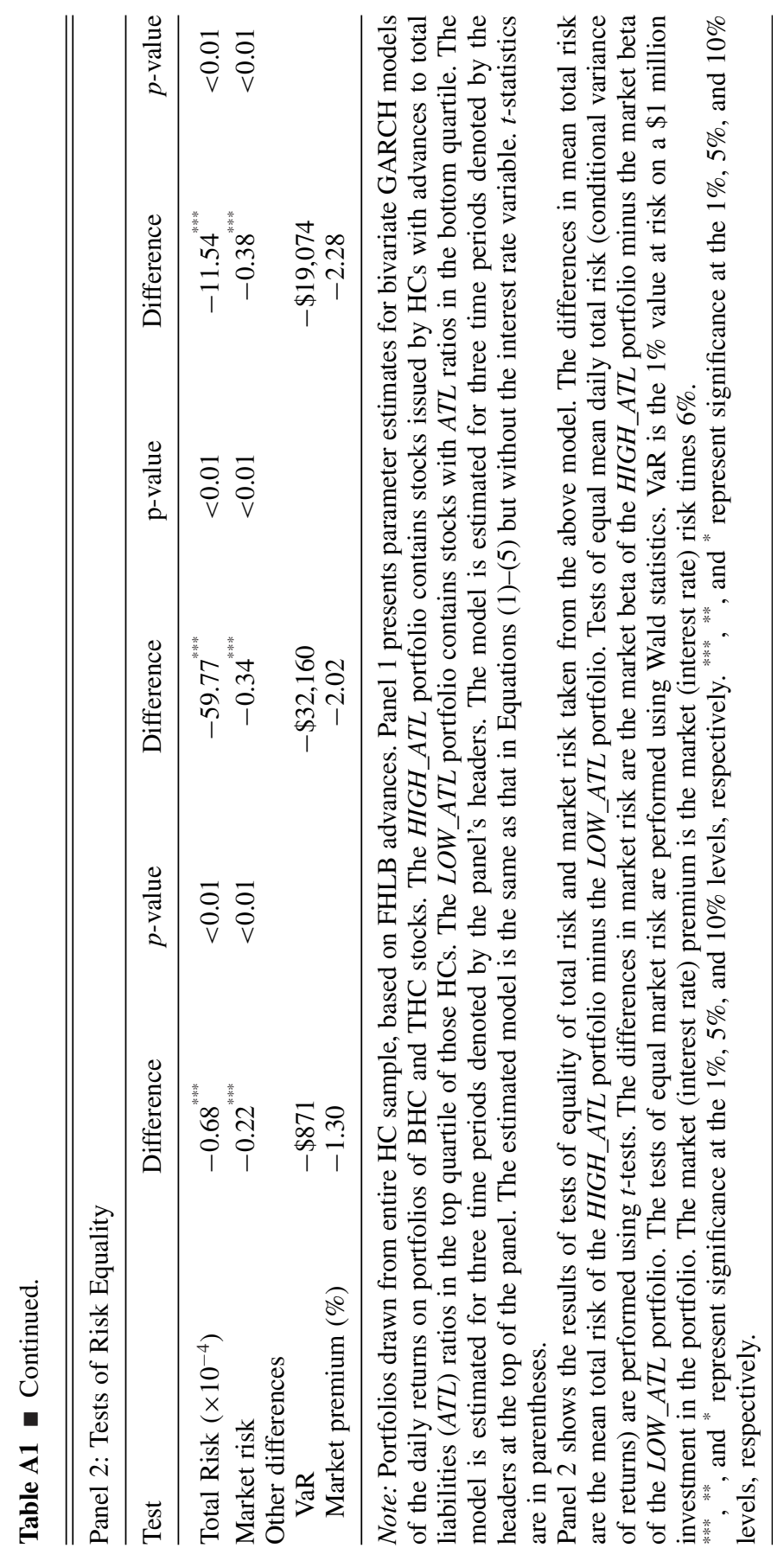




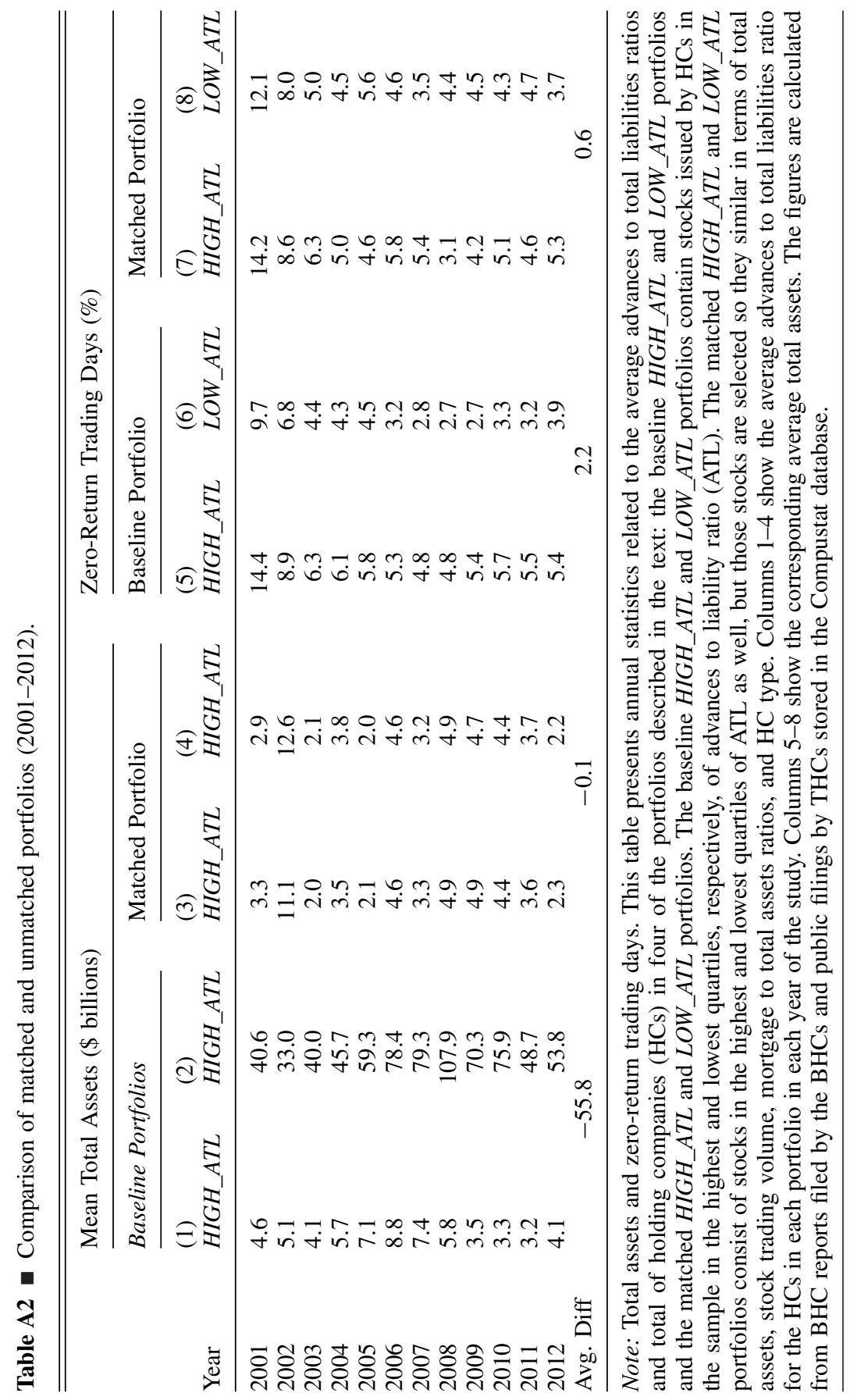




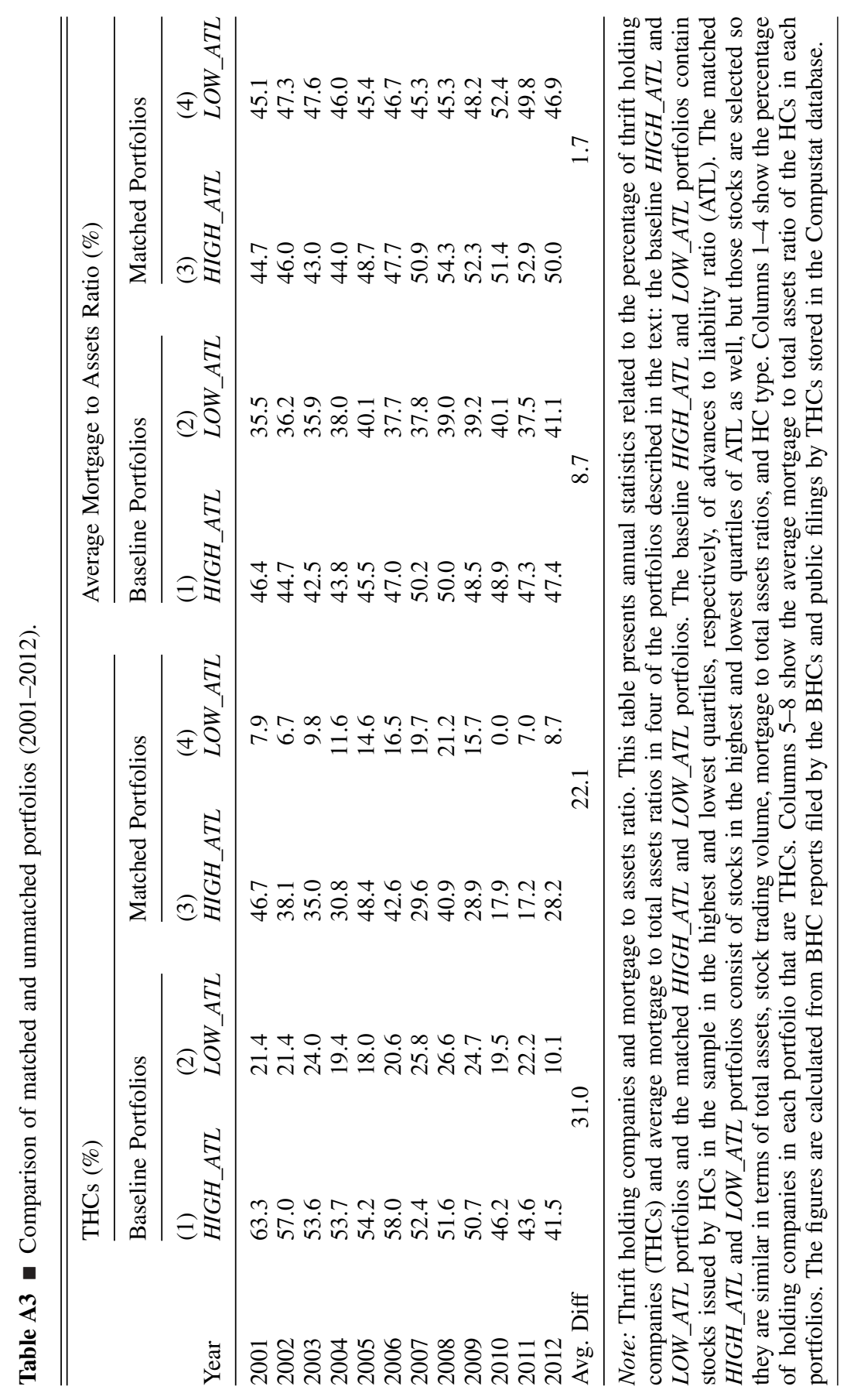




\section{Appendix B: Matched Portfolio Formation and Results}

We form matched portfolios as follows: For each quarter, HC stocks in each quartile are listed in order of their mortgage to assets ratios. Based on total assets, average stock trading volume, $\mathrm{HC}$ type (THC or BHC), and mortgage to assets ratio for that quarter, the Euclidean distance is calculated between the first HC listed in the first ATL quartile and each HC in the fourth ATL quartile for that quarter. The $\mathrm{HC}$ from the first quartile is matched with its "nearest neighbor," the fourth-quartile HC that is separated from it by the smallest Euclidean distance. Each HC in the matched pair is then taken out of the sample, and the process is repeated for each HC in the first ATL quartile according to its position in the list. The entire process is repeated for each quarter. Although the matched HCs have total assets and average trading volumes near to each other in relative terms, in absolute terms they differ significantly with respect to total assets in some cases. We therefore exclude pairs for which the difference in total assets is greater than $25 \%$ and form our portfolios from the remaining pairs.

Table A2, columns 1-4, compares the mean total assets in each portfoliobaseline and matched-for each year. The matching process reduces the gap in total assets from tens of billions of dollars to hundreds of thousands. Forming portfolios from the matched pairs also has the virtue of balancing the presence in the portfolios of "too-big-to-fail" (TBTF) institutions. If a TBTF institution is in one portfolio, an $\mathrm{HC}$ with total assets within $25 \%$ of its total assetsand, thus, likely to also be TBTF-will be in the corresponding portfolio. Table A2, columns 5-8, compares the percentage of zero-return observations on all of the stocks in each portfolio-baseline and matched-for each year. The matched portfolios are considerably more similar than the baseline portfolios. For the baseline portfolios, HIGH_ATL always has a greater percentage of zero-volume and zero-return trading days than $L O W \_A T L$. But for the matched portfolios, the portfolio with a greater percentage of either measure varies from year to year. Table A3 compares the baseline and matched portfolios in terms of the percentage of THCs in each portfolio and average mortgage to assets ratio. The average difference in THC composition of each portfolio falls from $31.0 \%$ to $22.1 \%$. The average difference in mortgage to total assets ratios declines from $8.7 \%$ to $1.7 \%$. 